OPEN ACCESS

Edited by: Kenneth Joseph Friedman, The State University of New Jersey,

United States

Reviewed by: Dinesh Upadhya, Manipal Academy of Higher

Education, India

Anju Aggarwal,

University College of Medical

Sciences, India

*Correspondence:

Amy Proal

amy.proal@gmail.com

Specialty section:

This article was submitted to

Pediatric Neurology,

a section of the journal

Frontiers in Pediatrics

Received: 30 August 2018 Accepted: 14 November 2018 Published: 04 December 2018

Citation:

Proal A and Marshall T (2018) Myalgic Encephalomyelitis/Chronic Fatigue Syndrome in the Era of the Human Microbiome: Persistent Pathogens

Drive Chronic Symptoms by Interfering With Host Metabolism, Gene Expression, and Immunity, Front. Pediatr. 6:373 doi: 10.3389/fped.2018.00373

\section{Myalgic Encephalomyelitis/Chronic Fatigue Syndrome in the Era of the Human Microbiome: Persistent Pathogens Drive Chronic Symptoms by Interfering With Host Metabolism, Gene Expression, and Immunity}

\author{
Amy Proal* and Trevor Marshall \\ Autoimmunity Research Foundation, Thousand Oaks, CA, United States
}

The illness ME/CFS has been repeatedly tied to infectious agents such as Epstein Barr Virus. Expanding research on the human microbiome now allows ME/CFS-associated pathogens to be studied as interacting members of human microbiome communities. Humans harbor these vast ecosystems of bacteria, viruses and fungi in nearly all tissue and blood. Most well-studied inflammatory conditions are tied to dysbiosis or imbalance of the human microbiome. While gut microbiome dysbiosis has been identified in ME/CFS, microbes and viruses outside the gut can also contribute to the illness. Pathobionts, and their associated proteins/metabolites, often control human metabolism and gene expression in a manner that pushes the body toward a state of illness. Intracellular pathogens, including many associated with ME/CFS, drive microbiome dysbiosis by directly interfering with human transcription, translation, and DNA repair processes. Molecular mimicry between host and pathogen proteins/metabolites further complicates this interference. Other human pathogens disable mitochondria or dysregulate host nervous system signaling. Antibodies and/or clonal T cells identified in patients with ME/CFS are likely activated in response to these persistent microbiome pathogens. Different human pathogens have evolved similar survival mechanisms to disable the host immune response and host metabolic pathways. The metabolic dysfunction driven by these organisms can result in similar clusters of inflammatory symptoms. ME/CFS may be driven by this pathogen-induced dysfunction, with the nature of dysbiosis and symptom presentation varying based on a patient's unique infectious and environmental history. Under such conditions, patients would benefit from treatments that support the human immune system in an effort to reverse the infectious disease process.

Keywords: microbiome, dysbiosis, holobiont, pathobiont, autoantibody, ME/CFS, molecular mimicry, gut-brain axis 


\section{INTRODUCTION: ME/CFS ENTERS THE ERA OF THE HUMAN MICROBIOME}

Toward the end of a career spent studying persistent bacteria in chronic disease, microbiologist Gerald Domingue wrote, "It is unwise to dismiss the pathogenic capacities of any microbe in a patient with a mysterious disease" (1). This thinking greatly applies to the illness ME/CFS. ME/CFS is characterized by neuroinflammation, severe fatigue, excessive post-exertional exhaustion, disturbed sleep, flu-like episodes, cognitive problems, sensory hypersensitivity, muscle and joint pain, headache, bowel symptoms, and severe impairment of daily functioning (2). Severely ill individuals are often wheelchair dependent, bedridden, and unable to perform basic tasks of work or daily living.

The history of ME/CFS strongly suggests that infectious agents play a central role in driving the disease process. These include early associations with Epstein Barr Virus (EBV)/Human Herpes Virus 6 (HHV6), the relapsing-remitting nature of ME/CFS symptoms and antibodies/"autoantibodies" detected in patients with the disease $(3,4)$. A number of ME/CFS outbreaks have also been reported, in which numerous people in the same geographical location developed the illness simultaneously (2). Indeed, many ME/CFS patients present with symptoms after suffering from a severe bacterial or viral infection. These infections often correlate with travel to a foreign country or exposure to pollutants or molds, suggesting that such pathogens take advantage of factors that compromise the host immune system.

Chronic inflammation is a hallmark of persistent infection. Reports of cytokine activation in ME/CFS clarify that the disease is associated with an inflammatory response (5). Montoya et al. (6) found ME/CFS cytokine activation increased with disease severity, suggesting patients may struggle with a growing infectious burden over time. Other $\mathrm{ME} / \mathrm{CFS}$ research teams have identified various forms of mitochondrial dysfunction in patients with the illness (7). There are now dozens of well-characterized mechanisms by which bacteria and viruses dysregulate mitochondrial metabolism $(8,9)$.

Many research teams have searched for well-characterized single pathogens in patients with ME/CFS. These analyses often reveal elevated titers of IGG and IGM antibodies toward pathogens such as Epstein Barr Virus, Cytomegalovirus, Parvovirus 19 and M. pneumonia (2, 3, 10). Several teams have also attempted to identify a single novel pathogen that might drive the entire ME/CFS disease process. However, the discovery of the human microbiome now allows single microbes and viruses to be studied as members of complex communities. Humans harbor these vast ecosystems of bacteria, viruses and fungi in nearly all tissue and blood (11-14). Organisms in the microbiome continually interact with each other, and with the human genome, to regulate host metabolism and gene expression in both health and disease $(15,16)$.

A growing number of inflammatory disease states, including neurological conditions and cancers, are tied to dysbiosis or imbalance of these human microbiome communities (17-20). Gut microbiome dysbiosis has been identified in ME/CFS (21). This dysbiosis is characterized by changes in microbe species composition and/or diversity. Pathogens, or groups of pathogens, can promote dysbiosis by altering their gene expression in ways that promote virulence, immunosuppression and dysregulation of host genetic and metabolic pathways (22).

When seemingly disparate biomedical findings on ME/CFS are interpreted through the lens of these microbiome-based paradigms and platforms, a cohesive picture of the ME/CFS disease process emerges. ME/CFS may be driven by pathogeninduced dysfunction, with resulting microbiome dysbiosis varying based on a patient's unique infectious and environmental history. Under such conditions, patients would benefit from treatments that, like those now being developed for cancer, support the human immune system in an effort to reverse the inflammatory disease process.

\section{THE HUMAN MICROBIOME PERSISTS THROUGHOUT THE BODY}

In the USA, ME/CFS cases were first formally reported to the CDC in the 1980s (2). At the time, human microbes were typically only detected with culture-based laboratory methods. Then, around the year 2000, novel genome-based technologies began to revolutionize the field of microbiology $(23,24)$. These technologies identify microbes based on their DNA or RNA signatures rather than their ability to grow in the laboratory. The results of these genome-based analyses were remarkable: vast communities of microbes were identified in the human body that had been missed by the older culture-based techniques. These extensive ecosystems of bacteria, viruses, fungi, and archaea are collectively known as the human microbiome (25-27).

Today, so many novel microbes have been identified in Homo sapiens that our human cells are equivalent to or even outnumbered by those of our microbial inhabitants (28). The tens of millions of unique genes harbored by this microbiome dwarf the $\sim 20,500$ genes in the human genome $(12,29)$. For example, just one 2017 analysis of the human gut, skin, mouth, and vaginal microbiomes uncovered millions of previously unknown microbial genes (11). This has forced science to redefine the human condition. Humans are best described as holobionts, in which the microbial genomes and the human genome continually interact to regulate metabolism and immunity $(15,16)$.

Early human microbiome studies characterized microbial ecosystems in the gut and on mucosal surfaces. However, the microbiome has now been shown to extend to nearly every human body site. These include the lungs, the bladder, the placenta, the testes, and the uterus $[(19,30-33)]$. Jakobsen et al. (35) found that previously sterile implants removed from joints, bones, pacemakers, and skulls of symptom-free patients were colonized by a range of bacterial and fungal organisms. Another study demonstrated the presence of novel tissue specific bacterial DNA profiles in a variety of mouse organs including the brain, heart, liver, muscle and adipose tissue (36). 
Microbial communities also appear to persist in healthy human blood (37-39). A DNA virome was recently identified in healthy human blood (40). Another study reported both bacterial and fungal communities in the blood of healthy subjects. Analysis of these organisms was performed by microbial resuscitation of blood culturing and microscopy in addition to next generation DNA sequencing (41). Whittle et al. (42) recently characterized a human blood microbiome using a range of complementary molecular and classical molecular biology techniques. Another study identified a larger amount of bacterial rDNA in blood specimens from healthy individuals than in matched reagent controls (24).

Kowarsky et al. (14) detected over 3,000 previously unidentified viruses, bacteria, and fungi in human blood samples obtained from immunocompromised patients. The study almost doubled the total number of anelloviruses found in humans. In order to classify many of these organisms the team was forced to add new branches to the "tree of life." They concluded that the newly discovered microbes "may prove to be the cause of acute or chronic diseases that, to date, have unknown etiology."

The microbiome is inherited and evolves with the host. Babies are seeded in the womb, during birth, and after birth by extensive microbiome communities in the placenta, the vaginal canal, and breast milk, among other body sites $(43,44)$. Microbes/pathogens acquired from the external environment are further incorporated into the microbiome over time. For example, once acquired, Cytomegalovirus persists as a member of the microbiomewith a significant impact on host immunity. Brodin et al. (45) found that the lifelong need for the body to control CMV causes approximately $10 \%$ of all $\mathrm{T}$ cells in CMV+ individuals to be directed against the virus.

Immune cells and associated microbes can travel between the human body and brain via several newly discovered pathways that bypass the classical blood-brain barrier (46). Benias et al. (47) documented a previously uncharacterized fluidfilled lattice of collagen bundles that appears to connect all human tissues. This human interstitium drains directly into the lymph nodes. Two research teams have demonstrated the existence of a previously undiscovered meningeal lymphatic system $(46,48,49)$. The network's fluid pathways connect the cerebrospinal fluid and cervical lymph nodes directly to the brain.

\section{OUR UNDERSTANDING OF THE HUMAN MICROBIOME AND VIROME CONTINUES TO EVOLVE}

While great progress has been made in characterizing the human microbiome, our understanding of the body's microbial ecosystems is still in its infancy. Metagenomic analyses of the microbiome in all body sites regularly identify species or strains of bacteria, archaea, fungi, and/or viruses not previously understood to persist in Homo sapiens (13). For example, just one study of the bladder microbiome identified 129 previously unidentified viruses in subjects' urine samples (50).
New strains of known microbes are also regularly identified. For example, as of August 2018, the NCBI database contains $\sim 1,833$ Lactobacillus genomes, with newly characterized Lactobacillus genomes added on a weekly basis (51). Successful identification of these known or novel human organisms hinges on the careful choice of technology and methodology used for detection purposes (26). While the majority of human microbiome studies center on bacteria, awareness of viruses, fungi, and archaea has increased in recent years (52). For example, Manuela et al. (53) found an almost 1:1 ratio of archaeal to bacterial $16 \mathrm{~S}$ rRNA genes in human appendix and nose samples. Identification of this archaeome abundance and diversity required use of a very specific archaea-targeting methodology.

Viruses are the most abundant life forms on the planet and in the human body, but have been relatively hard to detect until very recently (54). Viruses that primarily infect bacteria, called bacteriophages, are particularly abundant in human microbiome communities. Nguyen et al. (55) estimate that $\sim 31$ billion bacteriophages traffic human tissue and blood on a daily basis. However, the human virome also harbors a plethora of human-associated viruses. Newberry et al. (56) are correct to assert that this human virome is understudied in $\mathrm{ME} / \mathrm{CFS}$.

Paez-Espino et al. (57) at the Joint Genome Institute have undertaken a large project called "Uncovering the Earth's Virome." The Project's goal is to better identify known and novel viruses in Earth's ecosystems including the human body. Viral identification requires the use of specific metagenomic tools, pipelines, and annotation platforms, with findings entered in the JGI IMG/VR Database (57). The Project is progressing at such a rapid pace that viral diversity in IMG/VR has more than tripled since August 2016 (58), (Figure 1). Nevertheless, the vast majority of the gene content (over 15 million genes in total) remains unknown or hypothetical.

We must subsequently consider the possibility that asyet unidentified microorganisms may contribute to chronic inflammatory conditions like ME/CFS. Failure to do so would be akin to studying $\sim 2 \%$ of the animals in the rainforest and arriving at firm conclusions about the entire ecosystem based on that information alone. Certain members of the human microbiome may also be difficult to detect based on their location and/or lifestyle. For example, Chen et al. (59) found that elevated cytokine expression in response to HSV-infected peripheral nerve ganglia persisted even when the virus entered a latent, non-replicating state.

While it is important to pursue identification of novel organisms in ME/CFS blood and tissue, ample data already exists on better-studied components of the microbiome. Microbial and viral survival strategies, virulence mechanisms and collective behaviors are also characterized by a high degree of functional redundancy $(60,61)$. We must accept the complexity inherent to the human microbiome and further study these common mechanisms of survival and persistence. We must examine microbe and viral activity, microbe and viral gene expression, and the myriad ways in which the proteins and metabolites created by 


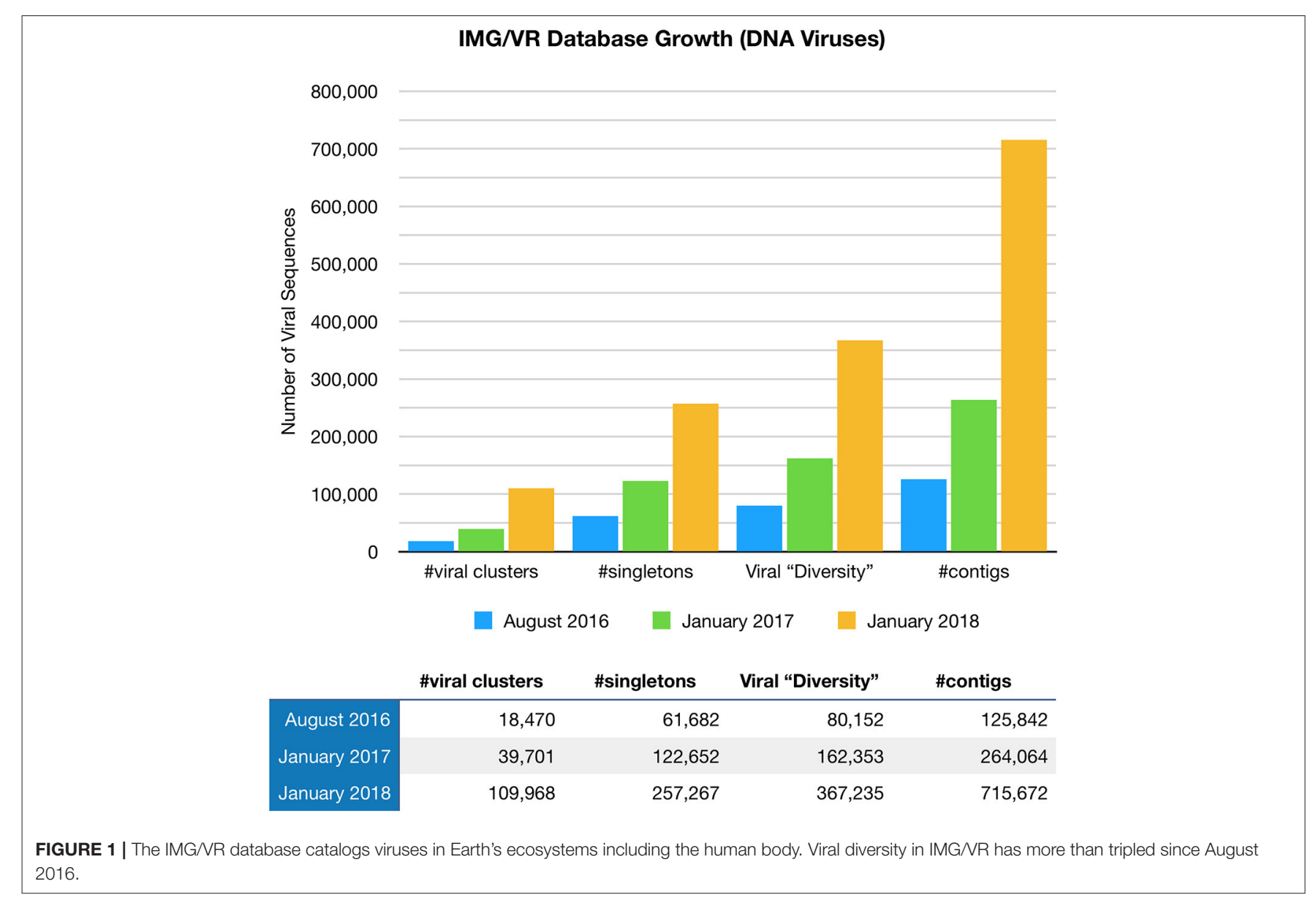

these organisms interact with the host immune system, the host genome, and each other.

\section{THE HUMAN HOLOBIONT: MICROBES AND THEIR METABOLITES MODULATE THE ACTIVITY OF HUMAN PATHWAYS}

The genes of our microbial inhabitants greatly outnumber the $\sim 20,500$ in the human genome. It follows that the majority of metabolites in Homo sapiens are produced or modified by the microbiome. Wikoff et al. (62) found a large effect of the gut microbiome on murine blood metabolites including antioxidants, toxins and amino acids. For example, production of the metabolite indole-3-propionic acid was completely dependent on the presence of gut microbes and could be established by colonization with the bacterium Clostridium sporogenes.

Many microbes, viruses and their corresponding proteins/metabolites directly modulate the activity of host metabolic, immune, and neurological pathways. In other words, the human holobiont is controlled by the human genome, our microbial/viral genomes and their respective metabolites working in tandem. A growing number of studies provide examples of this metabolic overlap. While many such studies have been conducted in mice, their general trends carry over to humans.

For example, ME/CFS is associated with natural killer (NK) cell abnormalities, including reduced natural killer cell activity (63). These findings must be interpreted to account for the fact that NK activity is modulated by the bacterial microbiome. One study found that bile acids modified by the gut microbiome impacted liver cell gene expression in a manner that controlled NK cell accumulation and anti-tumor activity (64). Similarly, a mixture of lactic acid bacteria from kefir increased the cytotoxicity of human NK KHYG-1 cells to human chronic leukemia cells and colorectal tumor cells (65). The microbiome and its metabolites also impact the activity of related immune cells. Rothhammer et al. (66) found that tryptophan created by the gut microbiome interacted with the AHR receptor on microglia/astrocytes. Subsequent changes in gene expression regulated communication between the two cell types.

Various forms of autonomic dysfunction are also common in ME/CFS $(67,68)$. It is subsequently important to consider that the microbiome may contribute to host blood pressure regulation. Pluznick et al. (69) found that gut microbiomederived Short Chain Fatty Acids such as acetate and propionate travel to the kidneys and blood vessels. There they impacted 
activity of Olfr78 and Gpr41, two host receptors that control circulation and blood flow.

\section{PATHOGENS AND THEIR PROTEINS/METABOLITES CAN DYSREGULATE HUMAN GENETIC AND METABOLIC PATHWAYS}

Microbial modulation of host pathways can also drive inflammatory disease processes. Pathogens and their associated proteins/metabolites control human metabolism and gene expression in a manner that can push the holobiont toward a state of imbalance and illness. For example, Rizzo et al. (70) found that Human Herpes Viruses 6A/6B infected NK cells. This infection significantly modified expression of key host miRNAs and transcription factors. Mycobacterium leprae has been shown to alter human gene expression in a manner that allows it to hijack and reprogram adult Schwann cells to a stem-like state (71). In a murine model of diabetes, Liu et al. (72) found that eLtaS, a protein created by $S$. aureus, prevented insulin from correctly binding its target receptor. This inhibited the phosphorylation of downstream signaling proteins and caused the mice in the study to develop impaired glucose tolerance.

The ability of pathogens to interfere with host metabolism is tied to the dynamics of the communities in which they persist. Like organisms in any ecosystem, human microbes constantly interact, both directly and indirectly. The proteins and metabolites they create are also in continual interplay. Communities of microbes often exhibit synergistic interactions for improved nutrient acquisition, protection from host defenses, and survival in an inflammatory environment (73). These include biofilm formation and cooperative signaling via quorum sensing peptides. Humphries et al. (74) recently reported that biofilm bacteria can additionally communicate via ion channel-mediated electrical signaling.

Even viruses seldom act as single entities. Diversity and equilibrium of the bacterial microbiome is regulated by bacteriophage predator-prey dynamics (75). Pfeiffer and Virgin (27) found that enteric viral virulence is regulated by the activity of neighboring bacteria, fungi, and even helminths. These processes are called "transkingdom interactions." For example, human norovirus can bind carbohydrate histo-blood group antigens present on certain bacterial cells. This facilitates the ability of norovirus to infect human B cells (76).

\section{MICROBIOME DYSBIOSIS}

Interacting microbes may contribute to dysbiosis or imbalance of microbiome communities (77). This dysbiosis is characterized by substantial shifts in community structure and diversity. In many cases, pathogens proliferate to inhabit niches once occupied by more innocuous microbes.

Most well-studied inflammatory disease states are tied to some form of microbiome dysbiosis. These include psoriatic arthritis, systemic lupus erythematosus, type 1 and 2 diabetes, Parkinson's disease and a growing number of cancers (34, 78,
79). The gut microbiome can initiate and promote colorectal cancer at all stages of tumorigenesis by acting as an inducer of DNA damage, generating epigenetic changes, regulating cell growth, and modulating host immune responses (80). The breast tissue microbiome of women with breast cancer has been shown to differ substantially in composition, virulence and diversity from that of healthy controls (81). Species composition of the bronchoalveolar microbiome shifted toward a more pathogenic state in patients with sarcoidosis (82). Alterations in the enteric virome were reported prior to disease onset in children susceptible to developing type 1 diabetes (83).

Several research teams have tied ME/CFS to bacterial gut microbiome dysbiosis. Giloteaux et al. (21) found that gut microbiome bacterial diversity was decreased in ME/CFS subjects compared to heathy controls. The team also noted increases in certain bacterial species associated with either pro-inflammatory or anti-inflammatory activity. Nagy-Szakal et al. (84) also analyzed the ME/CFS gut microbiome. The study detected seven gut bacterial species whose relative abundance differed from that of control subjects and were strongly associated with ME/CFS.

While these findings are of interest, gut microbiome composition is additionally impacted by a host of environmental variables that cause large shifts in the region's microbial ecosystems. These include geographic location, food consumption, and even time of day (85). Many research teams studying inflammatory conditions have struggled to isolate and/or replicate disease-induced gut microbiome dysbiosis in the face of this "noise." For example, Frémont et al. (86) found that intestinal microbiome species composition differed between patients with ME/CFS and healthy controls. However, significant changes in intestinal microbiome composition were also identified between control subjects from Norway and controls subjects from Belgium. This variation was proposed to arise from differences in diet between the two cultures.

Studies of the ME/CFS blood microbiome may be less subject to this environment-induced variability. Furthermore, identification of microbial and/or viral communities in ME/CFS blood would allow for a broader picture of possible infectious and inflammatory processes. For example, Giloteaux et al. (21) found that ME/CFS subjects had higher levels of bacterial lipopolysaccharides (LPS), LPS-binding proteins and soluble CD14 in blood. The team suggested that these inflammatory markers may indicate translocation of gut bacteria into the blood. However, the markers could also reflect the presence of bacteria in the blood itself.

The blood microbiome can be characterized if the microbial DNA/RNA in samples is first separated from that derived from the human genome. Olde Loohuis et al. (87) used RNA sequencing of reads from whole blood to analyze microbial communities in the blood of almost 200 patients with three neurological conditions: bipolar disorder, schizophrenia, and amyoytrophic lateral sclerosis. The team identified a wide range of bacterial and archaeal phyla in subjects with all three disease states. They observed increased microbial diversity in schizophrenia subjects compared to the two other groups, and replicated the finding in an independent dataset. Stephen Quake's cell-free DNA shotgun sequencing technologies can also 
characterize bacterial communities in human blood, and can be additionally extended to identify viruses and fungi (14).

Communities of microbes and viruses may also persist in ME/CFS brain tissue. Readhead et al. (88) recently detected a range of persistent viruses in the Alzheimer's brain. These included herpesviruses, torque teno viruses, adenoviruses, and coronaviruses. The Alzheimer's brain has also been shown to harbor bacterial and fungal communities $(89,90)$. Branton et al. (91) identified hundreds of bacteria and bacteriophage-derived samples in brain tissue removed from patients with epilepsy, and in brain samples obtained from HIV/AIDS patients after autopsy.

In fact, studies of the virome provide significantly extended context on microbiome community dynamics and disease processes. This is because bacteriophages (phages) infect, and subsequently modulate the activity of the bacterial microbiome (75). For example, Duerkop et al. (92) characterized the intestinal virome in a model of $\mathrm{T}$-cell-mediated murine colitis. The intestinal phage population changed in colitis, and transitioned from an ordered state to a stochastic dysbiosis. Phage populations that expanded during colitis were frequently connected to bacterial hosts that benefit from or are linked to intestinal inflammation. Tetz et al. (93) identified changes in the Parkinson's gut bacteriophage community. These included shifts in the phage/bacteria ratio of bacteria known to produce dopamine.

Species-level studies of the microbiome are also greatly enhanced by analyses that provide further context on disease activity. This is an important consideration because, in theory, the microbiome of a patient with ME/CFS could harbor the exact same microbial, viral and/or fungal species as that of a healthy subject. Yet many of these organisms could be acting very differently in patients with the disease. Species-level analyses of the ME/CFS microbiome must subsequently be accompanied by studies that characterize microbial and viral gene expression and/or metabolism.

\section{COMPOSITION OF THE HUMAN PROTEOME AND METABOLOME REFLECT MICROBIOME AND ACTIVITY}

Since many of the proteins and metabolites in the human holobiont are microbial in origin, composition of the ME/CFS proteome and metabolome change with microbiome species composition. Proteome and metabolome analyses additionally reflect microbiome activity. This is because microbes and viruses frequently alter their gene expression in ways that cause them to express different proteins and metabolites over time. The human genome and related epigenetic changes also contribute to the metabolic diversity, although the high level of redundancy between human and microbial metabolites can make the origin of these associations hard to pinpoint.

Schutzer et al. (94) demonstrated that the ME/CFS cerebrospinal proteome differs substantially from that of healthy controls (Figure 2). Indeed, 738 of 2,783 identified proteins $(26.5 \%)$ were unique to patients with ME/CFS, providing strong evidence that ME/CFS is indeed characterized

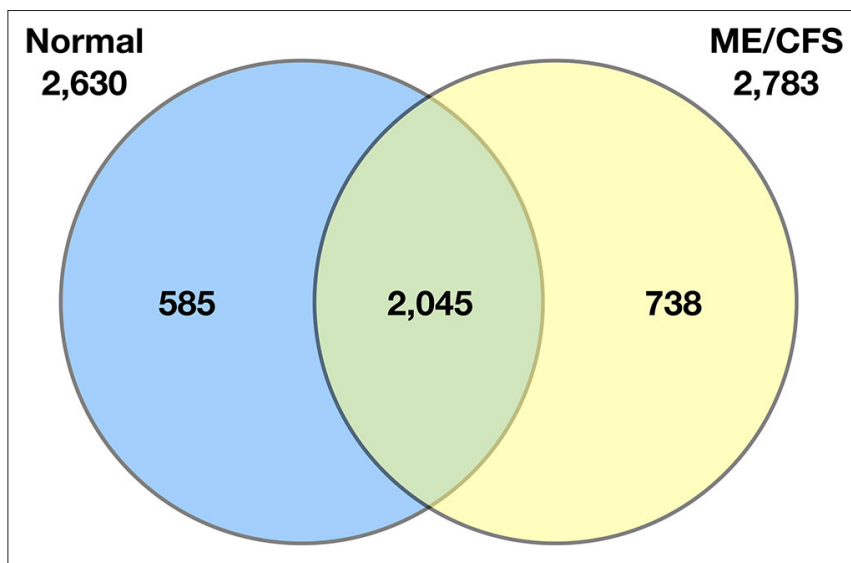

FIGURE 2 | Venn diagram of the qualitative distribution of proteins identified in cerebrospinal fluid from normal control subjects and ME/CFS subjects. Seven hundred and thirty eight of 2,783 identified proteins (26.5\%) were unique to patients with ME/CFS. The numbers of proteins for each category separately is shown outside the circles (2,630 for normal controls, 2,783 for ME/CFS) (94).

by microbiome dysbiosis in tissue and blood. Composition of the blood metabolome has also been shown to shift in ME/CFS. One such study reported elevated plasma levels of choline, carnitine, and complex lipid metabolites in ME/CFS patients (84). Another analysis demonstrated a sustained hypo-metabolic response in patients with the disease (95). This dour-like state can be driven by exposure to adverse environmental conditions, as would be expected if the ME/CFS immune system struggles to manage microbiome dysbiosis and associated pathogens.

Studies of the metabolome are often conducted in an attempt to identify disease-specific biomarkers. However, the metabolome can also be screened for metabolites that directly induce or suppress biological function in patients with a given illness. These studies help dissociate cause from effect and allow for possible modulation of disease phenotype. For example, Johnson et al. (96) investigated the metabolic influence of microbial biofilms on colon cancer tissue and related cancer occurrence. They found that up-regulation of a biofilm-derived polyamide metabolite enhanced both biofilm formation and cancer growth.

\section{MICROBES ACT DIFFERENTLY DEPENDING ON NEIGHBORING SPECIES AND IMMUNE STATUS}

Studies of microbiome activity must account for the fact that pathogens detected in patients with ME/CFS are also regularly identified in healthy subjects or in patients with related inflammatory conditions. This is particularly true of studies that have searched for EBV, HHV6, Cytomegalovirus, and other viruses able to be identified by PCR and/or antibody testing in ME/CFS cohorts. This same trend is likely to hold for lessstudied or unidentified human microbes and viruses. While these "overlapping" results are often viewed as problematic, they make sense in light of research that clarifies how differently 
microbes act depending on host immune status, neighboring species, and a wide range of other variables. For example, susceptibility to HIV infection has been shown to vary based on the species composition and activity of the bacterial vaginal microbiome (97).

Indeed, most human microbes are pathobionts: they can change their gene expression to act as pathogens under conditions of imbalance and immunosuppression (98-100). For example, S. pneumoniae can persist as a highly adapted commensal or a virulent pathogen depending on its ability to evade the host immune response (101). S. aureus causes a range of illnesses, from skin infections to life-threatening diseases such as endocarditis and meningitis. However, $\sim 30 \%$ of the healthy human population harbors $S$. aureus as a member of the normal nasal microbiome (102). S. aureus virulence in these communities is determined by a number of factors, including the signaling and competitive strategies employed by neighboring microbes.

The same is true of Escherichia coli (E. coli), which also persists in numerous forms. One study found that "commensal" E. coli could evolve into virulent clones in fewer than 500 generations (103). For most microbes, this evolution toward pathogenicity occurs via the acquisition of new genes or alteration of the current genome in a manner that induces gene loss (104). For example, loss of $m u c A$ increases the ability of Pseudomonas aeruginosa to evade phagocytosis and resist pulmonary clearance (105).

It should also be noted that every microbial species represents many different strains, each of which may vary in the set of genes it encodes or in the copy number of such genes. This intra-species variation endows each strain with distinct functional capacities, including differences in virulence, motility, nutrient utilization, and drug resistance (106). Greenblum et al. (106) identified extensive strainlevel copy-number variation across species in metagenomic samples obtained from patients with irritable bowel syndrome. This was especially true of genes tied to specific community functions, including functions related to community lifestyle. Differences in gene copy-number also impacted adaptive functions linked to obesity. Yao et al. (107) found that deletion of a single Bacteriodes gene-and the bile salt hydrolase it expresses-altered host metabolism in a manner that impacted weight management, circadian rhythm and immunity.

A microbe or a virus' location can also influence its activity. For example, much of the human population harbors HHV-6. However, in Alzheimer's disease, HHV-6A was recently identified in human brain tissue (88). There, its activity was shown capable of regulating host molecular, clinical, and neuropathological networks in a manner that can contribute to inflammation and neuronal loss. VanElzakker (108) has proposed that HHV-6 may also infect the vagus nerve in ME/CFS, resulting in altered gutbrain axis signaling in patients with the illness.

The human immune system also plays a central role in determining microbe and viral activity. A robust immune response is often capable of controlling pathogen virulence. However, if pathogens overcome the immune response, or the immune system is suppressed by medications, chemicals, or other environmental factors, pathobionts are more likely to alter their gene expression in a manner that promotes disease.

\section{PATHOBIONTS ALTER THEIR COLLECTIVE GENE EXPRESSION TO DRIVE DYSBIOSIS}

Pathobionts can subvert the human immune response by collectively altering their gene expression. Yost et al. (100) performed an excellent gene ontology (GO) enrichment analysis of the oral microbiome during periodontal progression. Over the two-month study period, changes in the metagenome of non-progressing sites were minor. However, active sites that progressed to periodontitis were characterized by numerous functional genomic signatures. In fact, the team reported a complete rearrangement at the metagenome level between baseline sites that progressed to periodontitis and those that did not.

GO terms associated with processes including peptidoglycan biosynthesis and potassium transport were highly enriched at baseline sites that later progressed to periodontitis. Genes controlling ciliary motility and CRISPR-associated proteins were also active during initial stages of disease progression. At the breakdown point, active sites expressed genes associated with ferrous iron transport and response to oxidative stress. Progression to periodontitis was also correlated with increased expression of putative virulence factors associated with a range of bacterial species. Mycoplasma, bacteriophage, and eukaryotic viral activity were higher in progressing sites compared to baseline samples.

The team concluded that periodontitis progression is driven by the whole oral microbial community and not just a few select pathogens. In effect, under conditions of increasing inflammation and imbalance, the entire oral community appeared to act together as a pathogen. Indeed, groups of bacteria not generally considered pathogens upregulated a large number of the putative virulence factors in active sites. These included Veillonella parvula, a microbe almost always associated with dental health.

\section{INTRACELLULAR PATHOGENS DRIVE MICROBIOME DYSBIOSIS}

Community-wide shifts in microbiome virulence are often driven by dominant pathogens-organisms that become established as central components of the microbiome while suppressing commensal growth and activity (109). In other cases, keystone pathogens promote inflammation even when present as quantitatively minor members of the microbiome. For example, $P$. gingivalis often comprises just $0.01 \%$ of periodontal biofilms, yet drives destructive changes in host-microbe interplay by profoundly impairing the innate immune response (110).

Pathogens able to persist inside the cells of the immune system are uniquely positioned to drive inflammatory disease (111). Indeed, most well-characterized pathogens, including many connected to $\mathrm{ME} / \mathrm{CFS}$, are capable of intracellular persistence (112). By surviving in this fashion, they can directly 


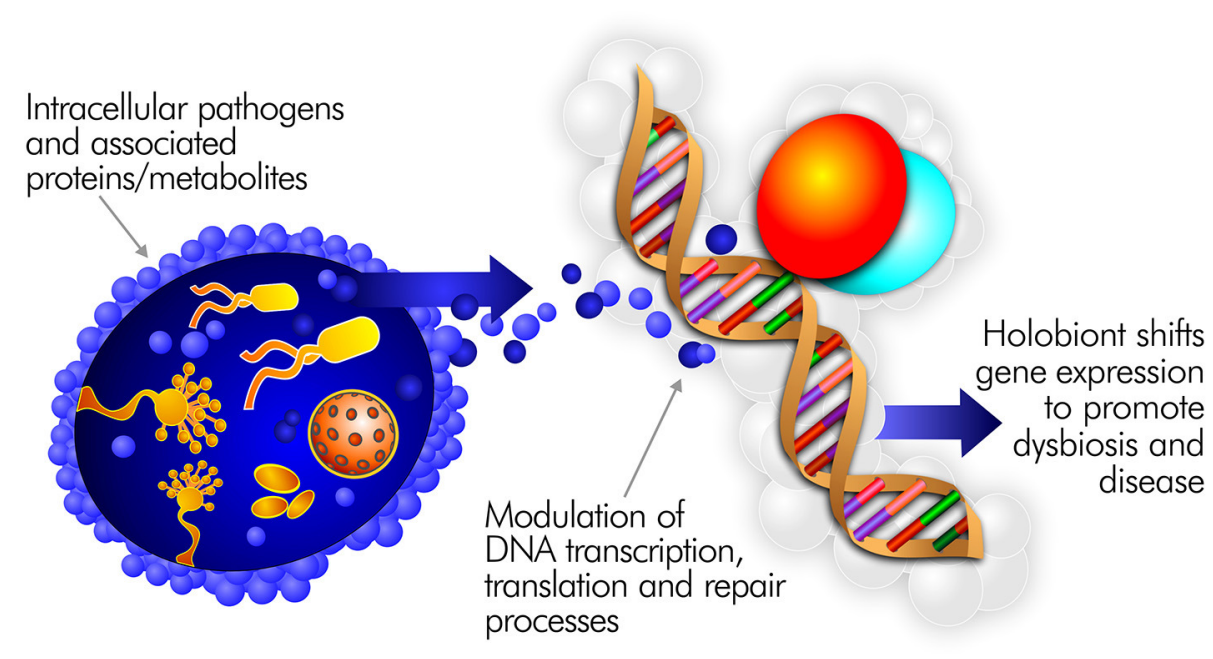

FIGURE 3 | Intracellular pathogens and the proteins/metabolites they express can directly interfere with human transcription, translation, and DNA repair processes.

interfere with human transcription, translation, and DNA repair processes (Figure 3). Pathogens in the cell cytoplasm may further dysregulate the epigenetic environment (113). For example, upon infecting a macrophage, Mycobacterium tuberculosis alters the expression of 463 human genes (114). H. pylori infection predisposes to genomic instability and DNA damage, including double strand breaks (115). EBV infection of B cells can also promote persistent damage to human DNA (116).

The thousands of metabolites and proteins expressed by intracellular pathogens also interact with the host genome, further modifying human gene expression in a manner that promotes disease. Even bacterial quorum sensing peptides can dysregulate human pathway activity. Wynendaele et al. (117) found that quorum sensing molecules created by gramnegative bacteria altered human gene expression in a manner that promoted in vitro angiogeneisis, tumor growth, and neovascularization in colon cancer.

Intracellular pathogens can also travel between cells via recently characterized tunneling nanotubules (TNTs) $(118,119)$. These cytoplasmic extensions of dendritic cells, glial cells and related human cells allow for the intracellular transfer of microRNAs, messenger RNAs, prions, viruses, and even whole organelles such as mitochondria $(120,121)$. For example, HIVinduced tunneling nanotubule formation appears to mediate approximately half of HIV virus spread among monocytederived macrophages (119).

\section{MOLECULAR MIMICRY}

Dysfunction driven by intracellular infection is compounded by the fact that microbial proteins and metabolites are often identical or similar in structure to those created by their human hosts. The molecular mimicry or sequence homology between these proteins and metabolites makes it increasingly difficult for the human holobiont to recognize "foreign" from "self."
For example, Altindis et al. (122) found that viruses carry sequences with significant homology to human insulin-like growth factors (VILPs). These VILPs can bind human and murine IGF-1 receptors in vitro, resulting in autophosphorylation and downstream signaling. E. coli harbors a large, diverse network of proteins that actively promote endogenous DNA damage in cells (123). However, at least 280 of these DNA-damaging proteins have human homologs that also promote DNA damage and mutagenesis in the human host.

Indeed, redundancy between human and microbial metabolites, proteins, and pathways is so great that the potential for molecular mimicry to contribute to host immune and metabolic dysfunction is semi-infinite. For example, viral vesicles and human extracellular vesicles (EVs) share considerable structural and functional similarity (124). These similarities are so extensive that it is difficult to distinguish EVs from (noninfectious) viruses.

\section{DIFFERENT PATHOGENS EMPLOY COMMON SURVIVAL STRATEGIES}

Many pathogens employ common survival mechanisms to persist in host cells, tissue and blood. The metabolic dysfunction driven by these different microbes and viruses can result in similar clusters of human inflammatory symptoms. The ability of various pathogens to dysregulate activity of the Vitamin D Nuclear Receptor (VDR) is an excellent example of how different microbes can drive similar disease processes. The VDR regulates expression of hundreds of human genes, many of which regulate inflammatory and malignant processes $(125,126)$. The receptor also controls signaling of TLR2 and several families of antimicrobial peptides including cathelicidin (LL-37) (127). Pathogens capable of slowing VDR activity can subsequently facilitate their survival by slowing the innate immune response. 


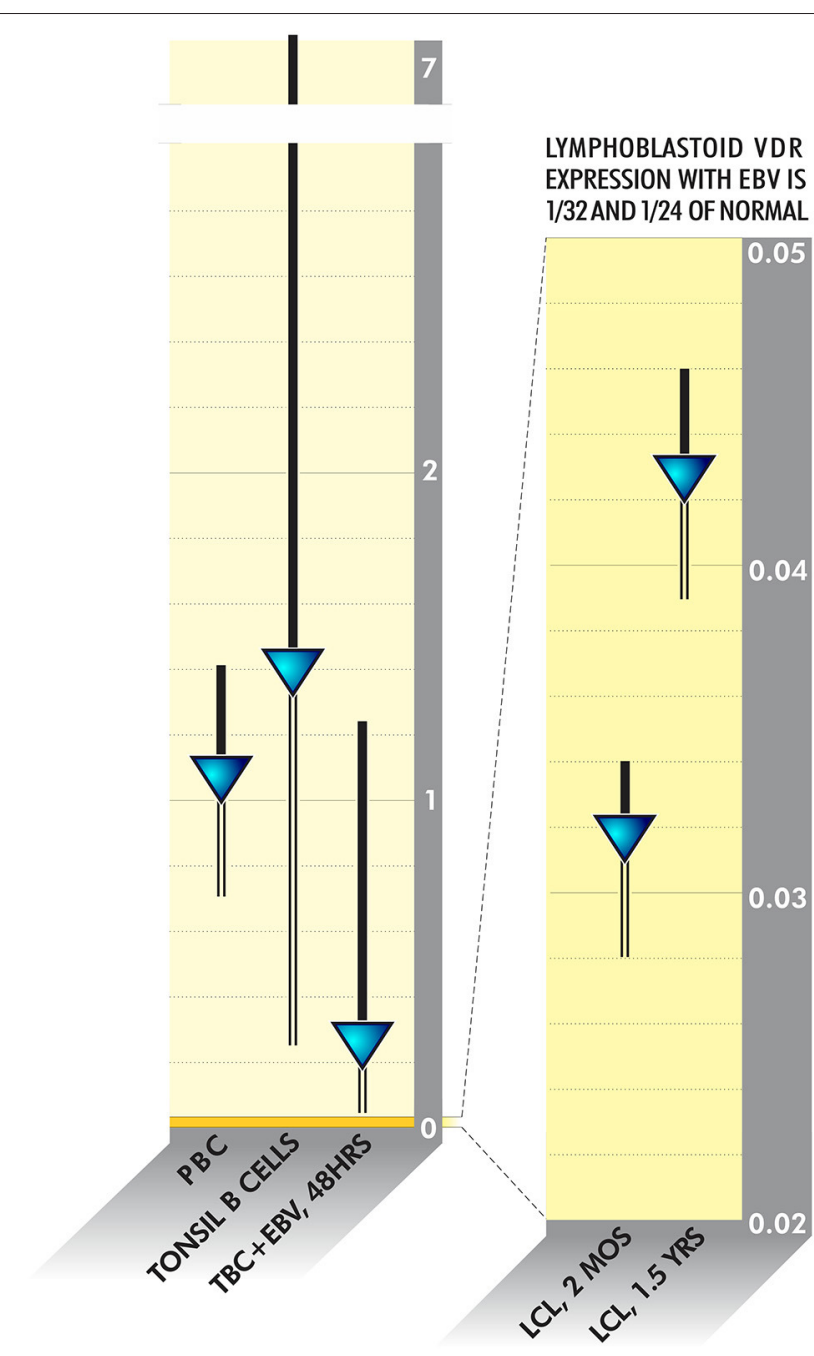

FIGURE 4 | VDR activity is downregulated as much as 20 times in Epstein Barr Virus-infected lymphoblastoid cell lines (128).

Pathogens frequently linked to ME/CFS or inflammatory disease have evolved to survive in this fashion. VDR activity is downregulated as much as 20 times in Epstein Barr Virus-infected lymphoblastoid cell lines (128) (Figure 4). HIV, M. tuberculosis Cytomegalovirus, Borrelia burgdorferi and Mycobacterium leprae additionally dysregulate VDR activity to various degrees $(114,129-132)$. The fungus Aspergillus fumigatus secretes a gliotoxin that significantly downregulates VDR expression (133). Because disabling the innate immune system via the VDR pathway is such a logical survival mechanism, other uncharacterized bacteria, viruses or fungi may have also evolved to dysregulate receptor activity.

It follows that ME/CFS patients with similar symptoms may not always test positive for the same mix of pathogens and/or communities of pathobionts. Similarly, composition of the ME/CFS microbiome, proteome and metabolome should be expected to differ somewhat from study to study. Instead of worrying about these inconsistencies, the ME/CFS research community should strive to better characterize even more common mechanisms of pathogen survival and persistence.

\section{THE IMMUNE RESPONSE CHANGES IN RESPONSE TO PATHOGEN ACTIVITY}

The ability of pathogens to disable the host immune response extends far beyond the VDR pathway. Pushalkar et al. (134) identified a distinct and abundant pancreatic microbiome associated with progressive pancreatic cancer. This dysbiotic microbiome drove oncogenesis by suppressing macrophage differentiation and $\mathrm{T}$ cell activity. Another study found that Candida albicans's transition from extracellular to intracellular pathogen was accompanied by a coordinated, time-dependent shift in gene expression for both host and fungus (135). These gene expression changes led to a gradual decline in proinflammatory cytokine activation by the host immune system.

These findings shed light on a recent ME/CFS study. Hornig et al. (5) reported distinct alterations in plasma immune signatures-including prominent activation of both pro-and anti-inflammatory cytokines-early in the course of ME/CFS. However, these alterations were not observed in subjects with a longer duration of illness. There are a number of explanations for Hornig's observations. ME/CFS-associated pathogens may gradually alter their gene activity to persist in more latent, intracellular forms less recognized by the host immune system. Or, in early-stage ME/CFS, the immune system may actively attempt to target a growing infectious burden. Over time however, pathogens in the microbiome may disable the immune response to a point where "immune exhaustion" occurs $(136,137)$. Immunopathology and cytokine production would subsequently drop. The resulting disease state could be compared to a garden, in which healthy plants become progressively stifled by others, such as kudzu vine.

\section{"ACUTE" PATHOGENS CAN SURVIVE IN PERSISTENT FORMS THAT DRIVE CHRONIC SYMPTOMS}

Many research teams are studying how "acute" pathogens (i.e., well-characterized agents associated with known infectious diseases) can cause chronic symptoms by persisting in latent forms. These include Zika, Borrelia burgdorferi, influenza, and other well-characterized viruses and bacteria (138). Zika was shown capable of persisting in the cerebrospinal fluid (CSF) and lymph nodes of infected rhesus monkeys for months after the virus had been cleared from mucosal secretions, peripheral blood and urine (139). Viral persistence in both the lymph nodes and CSF was correlated with upregulation of genes involved in pro-inflammatory and anti-apoptotic pathways.

Tens of thousands of Ebola survivors have developed chronic symptoms months or years after initial infection (140). These "Post-Ebola Syndrome" symptoms include extreme fatigue, severe pain, eye problems, and a host of neurological issues. While the virus is hard to identify in the blood of such patients, Ebola has been detected in men's semen years after "recovery" (141). Another study found that, up to a month after initial infection, influenza viruses regulated the long-term expression of inflammatory and neuron/glia-specific genes in mice (142). This was associated with chronic neuroinflammation characterized by 
an increase in the number of activated microglia and impairment of spatial memory formation.

Persistent measles virus is associated with conditions such as Paget's disease, multiple sclerosis and Crohn's disease (143, 144). Measles virus RNA has been detected in blood, respiratory secretions, urine, and lymphoid tissue for weeks to months after clearance of the "acute" infection (145). Doi et al. (146) found that, in vitro, measles virus persistence correlated with viral transition from a lytic to non-lytic mode that allowed the virus to evade the host innate immune response.

Hundreds of studies demonstrate that acute bacterial pathogens can transition into latent forms that lack a classical cell wall (1). These persistent variants are referred to as L-form bacteria. Antibiotic use can induce persistent L-form growth. In fact, researchers create L-forms by deliberately culturing classical bacteria in conjunction with the beta-lactam antibiotics (147). One microarray analysis of L-form growth revealed upregulation of genes shared in common with persister cells and biofilms (148). L-form bacteria have been implicated in dozens of chronic conditions including rheumatoid arthritis, multiple sclerosis and sarcoidosis $(1,149,150)$.

A better understanding of these chronic sequelae would greatly benefit the ME/CFS community, since a similar chronic progression of symptoms is frequently documented in ME/CFS. At different points in history, ME/CFS has been called "PostPolio Syndrome," "Chronic Mononucleosis Syndrome" and "Post-Viral Syndrome" due to the fact that chronic symptoms are often noted after acute infection with Polio Virus, Epstein Barr Virus, influenza or a range of other pathogens (151-153). Chia et al. (154) found that patients with acute enterovirus infection went on to develop a multitude of chronic symptoms consistent with an ME/CFS diagnosis. Years after the initial infection, enterovirus protein and RNA were still present in these patients' stomach biopsies.

It is clear that novel methodologies may be required to best identify pathogens in their latent forms. Pathogens that persist inside human immune cells and associated tunneling nanotubuoles have been particularly hard to detect. When persistent Zika virus was identified in rhesus monkeys, Zikaspecific antibodies were not detected in the CSF, despite prolonged and robust responses in peripheral blood. This suggested an additional mechanism for viral persistence in certain "anotomic sanctuaries." Modern living has also increased the likelihood that "acute" infections may generate chronic sequelae. Before the advent of antibiotics, steroid medications and childhood vaccines, almost half of all children under the age of five died from acute infectious disease (45). Today, most individuals in first-world countries survive repeated acute infections over the course of decades.

\section{UNIQUE INFECTIOUS HISTORY SHAPES ME/CFS DISEASE PROGRESSION}

While certain dominant or keystone pathogens may be reliably identified in patients with ME/CFS, composition of the ME/CFS microbiome will likely differ between patients.
Even in HIV/AIDS, where an easily detected virus dysregulates immunity, disease symptoms reflect a mix of those driven by HIV, and those driven by "co-infectious" agents able to take advantage of the immunocompromised host (155). No two patients with HIV/AIDS are expected to harbor the same mix of these additional persistent bacteria, fungi, and viruses. The same is true of most cancers, an increasing number of which are now tied to severe microbiome dysbiosis (34). It is widely accepted that no two cancers are alike, and any tumor-associated microbiome is expected to differ somewhat among individual study subjects (156).

This same pattern, in which unique infectious history impacts symptom presentation may also occur in ME/CFS. A recent study by Brodin et al. (45) demonstrated the profound impact of infectious history on host immunity. The team performed a systems-level analysis of 210 healthy twins between the ages of 8 and 82. They measured 204 immune parameters, including cell population frequencies, cytokine responses, and serum proteins, and found that $77 \%$ of these are dominated, and $58 \%$ almost completely determined, by non-heritable environmental influences. Many of these parameters became more variable with age, emphasizing the cumulative influence of environmental exposure.

The team also calculated how acquisition of just one chronic pathogen-cytomegalovirus (CMV)-conditions the immune response. Identical twins discordant for CMV infection showed greatly reduced correlations for many immune cell frequencies, cell signaling responses, and cytokine concentrations. In general, the influence of CMV was so broad that it affected 119 of the 204 measurements dispersed throughout the immune network. These and related findings led Brodin and team to conclude that the immune response is "very much shaped by the environment and most likely by the many different microbes an individual encounters in their lifetime."

\section{COULD "SUCCESSIVE INFECTION CONTRIBUTE TO ME/CFS?"}

The above suggests that ME/CFS may be driven by a process we have termed "successive infection." During successive infection, an "acute" infection or "initial immunosuppressive event" dysregulates the host immune system. This makes it easier for microbes to subvert the immune response by acting as polymicrobial entities. Pathobionts alter their gene expression to better promote community-wide virulence. Infected human cells fail to correctly express human metabolites in the presence of pathogen-generated proteins, metabolites, and enzymes. Dysfunction driven by molecular mimicry increases. Certain pathogens may infect mitochondria or central nervous system tissue. Intracellular pathogens slow the human immune response, causing the host to more easily acquire other infectious agents. This creates a snowball effect in which the microbiome becomes increasingly dysbiotic as the strength of the immune response weakens over time. 
Eventually, the human host may present with symptoms characteristic of ME/CFS or a related inflammatory diagnosis. The unique symptoms any one patient develops are expected to vary based on the species, strain, virulence, and location of the pathogens driving dysbiosis, along with the myriad ways in which the metabolites and proteins created by these organisms cause dysfunction by interacting with those of the host.

Early childhood infections may predispose to dysbiosis at a later date (157). For example, measles depletes host B and T lymphocytes for up to 2-3 years after initial infection. This immunosuppression can reset previously acquired immunity and renders the host more susceptible to other pathogens (158). In other cases, a toxic environmental exposure, infection during surgery or the difficulty of enduring a traumatic event may weaken the immune response to a point where previously subclinical infections become active. ME/CFS outbreaks, in which numerous patients developed the illness at relatively the same time, may well represent this phenomenon at work.

The successive infectious process may even begin in the womb. Depending on the health of the parent, founding microbiome communities in the placenta, vagina and breast milk may already be dysbiotic. Cabrera-Rubio et al. (159) found that the breast milk microbiome of obese mothers tended to contain a different and less diverse bacterial community then that of normal-weight mothers. Pathogens in the placental microbiome can alter methylation of human DNA in a manner that may negatively impact the later life disease of premature babies (160).

Many aspects of modern living can additionally drive successive infection. Antibiotic use disrupts the ecology of the human microbiome (161). Antibiotic resistance genes from farm animals and produce are regularly transferred into the human food supply (162). Electromagnetic radiation has been shown to lower immunity (163). The immunosuppressive biologics and supplements often prescribed for inflammatory disease further allow pathobionts in the microbiome to proliferate. For example, Diaz et al. (164) found that the salivary bacteriome of patients taking immunosuppressive biologics was more permissive to the growth of oral opportunistic pathogens.

Modern society also exposes the average person to pathogens our recent ancestors were unlikely to encounter. International airports harbor pathogens from across the globe (165). Food products, and the microbes they contain, are frequently imported from foreign destinations (166). One study found a range of opportunistic pathogens enriched in showerhead biofilms (167). Numerous pathogens were identified in commonly smoked cigarettes (168). Many such pathogens are capable of persisting in human microbiome ecosystems, where the host may lack immunity toward their presence.

\section{ME/CFS PATIENTS SHOULD BE STUDIED IN CONCERT WITH RELATED INFLAMMATORY CONDITIONS}

$\mathrm{ME} / \mathrm{CFS}$ is a spectrum disorder with a diagnostic criterion that includes a range of physical and neurological symptoms (2). If successive infection contributes to ME/CFS, this variability in symptom presentation is expected. Furthermore, factoring "unique infectious history" into the disease process helps explain why patients with ME/CFS often suffer from a multitude of symptoms not included in the official diagnostic criteria.

Because patients with ME/CFS suffer from such diverse symptoms, it has been argued that they should be grouped into separately studied "subgroups" (169). In some cases this makes sense. For example, studies that distinguish earlystage/late-stage ME/CFS patients may further elucidate how the immune response is modified by the microbiome over time. However, if successive infection contributes to ME/CFS, future research should also focus on better understanding the common pathogenesis shared by all subjects.

Indeed, successive infection may contribute to other conditions tied to microbiome dysbiosis, persistent infection, and adverse environmental exposure. ME/CFS should be studied in concert with these other conditions, which include Gulf War Syndrome, Ehlers-Danlos Syndrome, Chronic Lyme Disease, and fibromyalgia among others (170-174). The high levels of comorbidity and symptom overlap between patients with $\mathrm{ME} / \mathrm{CFS}$ and these related inflammatory diagnoses strengthens this assumption.

\section{"AUTOANTIBODIES" IN ME/CFS ARE LIKELY CREATED IN RESPONSE TO PERSISTENT PATHOGENS}

A number of autoantibodies have been detected in patients with ME/CFS (4). This has led some research teams to postulate that ME/CFS should be regarded as an "autoimmune" disorder (175). However, the classical "theory of autoimmunity" is in the process of being re-evaluated $(78,176)$. Increasing evidence suggests that "autoantibodies" are actually created in response to chronic, persistent microbiome pathogens. Under such conditions molecular mimicry or structural homology between pathogen and host proteins can result in "collateral damage" toward human tissue. For example, Vojdani et al. (177) found that 25 different Alzheimer's-associated pathogens or their molecules could react with antibodies against amyloid beta via molecular mimicry or the binding of bacterial toxins to amyloid beta.

A growing body of research documents "autoantibody" production in response to a range of bacterial, viral and fungal pathogens/pathobionts. These pathogens are not shortterm "triggers" but persist as members of complex microbiome communities. For example, "autoantibody" production was recently tied to microbiome pathobiont Enterococcus gallinarum. Manfredo et al. (178) detected E. galinarum in the mesenteric veins, lymph nodes, spleens and livers of mice made genetically prone to autoimmunity. In these mice, the bacterium initiated the production of "autoantibodies," inflammation and activated T cells. However, this "autoantibody" production stopped when E. gallinarum's growth was suppressed with the antibiotic vancomycin or with an intramuscular vaccine. In addition, E. gallinarum-specific DNA was recovered from liver biopsies 
of human autoimmune patients, and co-cultures with human hepatocytes replicated the murine findings.

Indeed, many pathogens can drive the activated or clonal $\mathrm{T}$ cell expansion often associated with "autoimmune" conditions. For example, Tuffs et al. (179) found that S. aureus endotoxins triggered uncontrolled activation of $\mathrm{T}$ cells. This led to a proinflammatory cytokine storm that accounted for both $\mathrm{T}$ cell activation and related inflammation.

\section{THE GUT-BRAIN AXIS AND THE BRAIN MICROBIOME}

Microbes and their metabolites control bidirectional signaling between the gut and the brain via pathways collectively known as the gut-brain axis (180). The gut-brain axis involves various afferent and efferent pathways including the vagus nerve, with signaling impacting neural, endocrine, and immune processes. The gut's enteric nervous system contains over 100 million neurons-more than in either the peripheral nervous system or spinal cord (181). It follows that gut microbiome dysbiosis may modulate brain activity. For example, Sampson et al. (79) transplanted fecal samples from patients with Parkinson's disease into germ-free mice. These mice, and not controls, exhibited physical symptoms associated with Parkinson's.

However, there is also growing evidence that humans may harbor a brain microbiome. Researchers at Harvard University are characterizing this ecosystem as part of the ongoing "Brain Microbiome Project." In what marks a major paradigm shift, multiple research teams have shown that both amyloid beta and prion protein (PrP) are potent antimicrobial peptides $(182,183)$. Amyloid beta exhibited antimicrobial activity against a range of common microorganisms with a potency equivalent to, and in some cases greater than, cathelicidin (LL-37) (184). These pathogens included S. typhimurium, Candida albicans and, more recently, a number of herpesviruses capable of persisting in the Alzheimer's brain (88, 185).

The findings strongly suggest that amyloid beta and $\operatorname{PrP}$ are not useless byproducts of abnormal brain catabolism. Rather, they appear to form a mediated response of the innate immune system toward infectious agents in brain tissue (186). A number of brain abnormalities have been reported in patents with ME/CFS (187). These findings must be interpreted in light of these novel infection-based paradigms and in concert with emerging data on the brain microbiome.

\section{WHAT ABOUT THE HUMAN GENOME?}

In a study of aortic aneurysms, Gottlieb et al. (188) reported that BAK1 SNP-containing alleles were detected in aortic tissue but not in blood samples from the same patients. More recently Ursini et al. (189) found that schizophrenia gene risk loci that interact with early-life complications are highly expressed in the placenta. However, these loci were differentially expressed in placentas from women who suffered complications during pregnancy. They were also differentially upregulated in placentae from male compared with female offspring.
These and related findings strongly suggest that the environment can select for human genome activity. For example, Harley et al. (190) found that in EBV infected cells, EBNA2 and its transcription factors modulated the activity of human genes associated with risk for multiple sclerosis, rheumatoid arthritis, type 1 diabetes and other conditions. In fact, nearly half of systemic lupus erythematosus risk loci were occupied by EBNA2 and co-clustering human transcription factors.

Studies of the human genome must also account for the full extent of microbial DNA and RNA in human tissue and blood. If a genomic assembler fails to account for this contamination, chances of a false positive single nucleotide polymorphism (SNP) increase significantly during analysis (191). Contamination with even a small amount of microbial DNA/RNA - just one or two base pairs of difference-is enough to cause significant statistical errors in this fashion.

\section{IMMUNOSTIMULATION IN THE TREATMENT OF ME/CFS}

If $\mathrm{ME} / \mathrm{CFS}$ is driven by successive infection, treatments that support or activate the human immune system could improve microbiome health by allowing patients to better target persistent pathogens. Development of such therapies should be a priority for the ME/CFS research community. However, most immunostimulative treatments that target pathogens are characterized by immunopathology - a cascade of reactions in which inflammation, cytokine release and endotoxin release are generated as part of the immune system's response to microbial death (192-194). The death of intracellular pathogens is particularly difficult for the host to manage, as the body must deal with debris generated from apoptosis. Inflammation is also generated in response to bacterial cell wall components including the endotoxin lipopolysaccharide of Gram-negative strains (192). Luckily, immunopathology-generated symptoms are generally temporary in nature, and tend to subside as an increasing number of pathogens are eradicated.

Temporary immunopathology resulting from antimicrobial treatment has been documented for over a century, with symptoms varying depending on the nature of targeted pathogens. First referred to as the Jarisch-Herxheimer reaction, the phenomenon was originally observed during treatment of syphilis with mercury and penicillin $(195,196)$. The JarischHerxheimer reaction/immunopathology has since been noted in a broad spectrum of chronic inflammatory conditions including tuberculosis and Brucellosis (197). Short-term immunopathology is also a central feature of acute infection. If a patient develops the flu, inflammatory symptoms increase as the immune system releases cytokines and chemokines in response to the infecting virus.

HIV/AIDS patients undergo a form of immunopathology called Immune Reconstitution Inflammatory Syndrome (IRIS) following treatment with Combination Antiretroviral Therapy (ART) (198). IRIS occurs as ART enables the host immune system to better target pathogens acquired during previous periods of 
HIV-driven immunosuppression. A range of well-characterized pathogens have been linked to IRIS including the herpesviruses and M. tuberculosis (193). However, the inflammatory reaction is also noted in culture-negative patients, suggesting IRIS may also involve novel or uncharacterized pathogens (198).

Over the past decade, in concert with our clinical collaborators, we developed an immunostimulative therapy used to treat patients with a range of chronic inflammatory conditions (200). Treatment centers on the use of a putative VDR agonist in the form of olmesartan medoxomil, with the goal of reactivating components of innate immunity under VDR control. In 2013, we published a series of case histories demonstrating improvement in ME/CFS patients administered this treatment (199). However, all ME/CFS subjects administered the therapy experienced immunopathology and associated inflammatory symptom increases that lasted for many years. As a general trend, patients administered the treatment during earlier stages of disease experienced less immunopathology, emphasizing the need for immunostimulative therapies to be used in a predictive and even preventative fashion.

While some ME/CFS physicians may feel uneasy about the suffering induced by immunopathology, other research communities have become accustomed to treatments that cause temporary discomfort. Novel cancer immunotherapies also generate immunopathology by activating patient $\mathrm{T}$ cells. This allows the immune system to better target malignant tumors $(194,201)$. The resulting "cytokine release syndrome" leads to profound, temporary, symptom increases. However, these increased symptoms are considered acceptable, as patients who endure the reaction are more likely to enter a state of remission. Since many forms of cancer are tied to severe microbiome dysbiosis, at least part of the "cytokine release syndrome" may result from the death of persistent pathogens.

\section{DISCUSSION}

The history of ME/CFS strongly suggests that infectious agents play a central role in driving the disease process. However, the discovery of the human microbiome has revolutionized the manner in which persistent infection and chronic inflammation are understood and studied. Humans harbor extensive microbiome communities of bacteria, viruses, and fungi in nearly all tissue and blood. The hundreds of millions of unique genes harbored by this microbiome dwarf the $\sim 20,500$ in the human genome. Humans are best described as holobionts, in which these microbial genomes and the human genome continually interact to regulate host gene expression, metabolism and immunity.

Many inflammatory disease states, including neurological conditions and cancers, are tied to dysbiosis or imbalance of human microbiome communities in various body sites. While gut microbiome dysbiosis has already been identified in ME/CFS, distinct microbial and viral communities may additionally persist in ME/CFS blood and brain tissue. Possible identification of these microbiomes should be a priority for the ME/CFS research community, but analysis requires the use of very specific technologies and methodologies.

Pathogens and their associated proteins/metabolites control human metabolism and gene expression in a manner that can push the human holobiont toward a state of illness. Studies of microbiome dysbiosis in ME/CFS must consider this microbe and viral activity. Most human microbes can alter their gene expression to act as pathogens under conditions of imbalance and immunosuppression. This pathobiont behavior is further determined by the activity and virulence of neighboring microbes. Patients with ME/CFS may harbor many of the same microbes and viruses as heathy individuals, yet these pathobionts may act with increased virulence in patients with the illness.

Intracellular pathogens, including several associated with ME/CFS, have been shown to directly interfere with human transcription, translation, and DNA repair processes. Molecular mimicry between host and pathogen proteins/metabolites further exacerbates this interference. Interacting microbes can also drive disease by changing their collective gene expression. Other pathogens disable mitochondria, or may infect central nervous system tissue in ways that dysregulate signaling via the gutbrain axis. Antibodies and/or clonal T cells identified in patients with ME/CFS are likely activated in response to many of these persistent microbiome pathogens.

Different pathogens have evolved similar survival mechanisms to disable the host immune response and/or host metabolic pathways. The metabolic dysfunction driven by these different microbes can result in similar clusters of inflammatory symptoms. ME/CFS may be driven by this pathogen-induced dysfunction, with the nature of dysbiosis and symptom presentation varying based on a patient's unique infectious and environmental history. An initial infection or environmental exposure weakens the host immune system. This makes it easier for pathobionts to subvert the immune response and interfere with host gene expression and metabolism. A snowball effect begins, in which the microbiome becomes increasingly dysbiotic as the strength of the immune response weakens over time. The unique symptoms any one ME/CFS patient develops are expected to vary depending on the location, species, strain and virulence of the pathogens driving this dysbiosis. Thus, while certain dominant or keystone pathogens may be identified in ME/CFS, composition of the ME/CFS microbiome, metabolome, and proteome should be expected to differ somewhat among individual patients.

These common mechanisms suggest that ME/CFS is best studied in concert with other chronic conditions tied to microbiome dysbiosis, persistent infection and adverse environmental exposure. These include fibromyalgia and Gulf War Syndrome, but also conditions like Post-Ebola Syndrome in which severe chronic symptoms develop after infection with an "acute" infectious agent that is able to persist in latent forms.

Treatments that support or activate the human immune system could allow ME/CFS patients to improve microbiome health by better targeting pathogens over time. Like the novel immunotherapies being developed for cancers, these immunostimulative therapies would be expected to generate 
temporary immunopathology. Institutional reviewers hesitant to approve immunopathology-based therapies should consider that ME/CFS quality of life is typically very low, with patients demonstrating a substantial increase in mortality from suicide (202).

It often takes patients years to receive a diagnosis of ME/CFS. This delay wastes a valuable period during which the immune system is most responsive to immunostimulatory treatment. Patients treated during earlier stage disease are also less likely to experience severe or long-lasting immunopathology. This suggests that immunostimulative therapies should be administered in a predictive and even preventative fashion. In addition, interventions or treatments that might help patients better manage the byproducts of immunopathology (bacterial LPS etc.) should become a priority for the research community.

The overall success of ME/CFS research also hinges on the scientific community's willingness to embrace the concept of the human holobiont. In ME/CFS, the immune response, metabolism, central nervous system, and human gene expression

\section{REFERENCES}

1. Domingue GJSr, Woody HB. Bacterial persistence and expression of disease. Clin Microbiol Rev. (1997) 10:320-44.

2. Rowe PC, Underhill RA, Friedman KJ, Gurwitt A, Medow MS, Schwartz MS, et al. Myalgic encephalomyelitis/chronic fatigue syndrome diagnosis and management in young people: a primer. Front Pediatr. (2017) 5:121. doi: 10.3389/fped.2017.00121

3. Chapenko S, Krumina A, Logina I, Rasa S, Chistjakovs M, Sultanova M, et al. Association of active human herpesvirus- $6,-7$ and parvovirus b19 infection with clinical outcomes in patients with myalgic encephalomyelitis/chronic fatigue syndrome. Adv Virol. (2012) 2012:205085. doi: 10.1155/2012/205085

4. Loebel M, Grabowski P, Heidecke H, Bauer S, Hanitsch LG, Wittke K, et al. Antibodies to $\beta$ adrenergic and muscarinic cholinergic receptors in patients with Chronic Fatigue Syndrome. Brain Behav Immun. (2016) 52:329. doi: 10.1016/j.bbi.2015.09.013

5. Hornig M, Montoya JG, Klimas NG, Levine S, Felsenstein D, Bateman L, et al. Distinct plasma immune signatures in ME/CFS are present early in the course of illness. Sci Adv. (2015) 1:e1400121. doi: 10.1126/sciadv.1400121

6. Montoya JG, Holmes TH, Anderson JN, Maecker HT, Rosenberg-Hasson Y, Valencia IJ, et al. Cytokine signature associated with disease severity in chronic fatigue syndrome patients. Proc Natl Acad Sci. (2017) 114:E7150-8. doi: 10.1073/pnas.1710519114

7. Myhill S, Booth NE, McLaren-Howard J. Chronic fatigue syndrome and mitochondrial dysfunction. Int J Clin Exp Med. (2009) 2:1-16.

8. Anand SK, Tikoo SK. Viruses as modulators of mitochondrial functions. $A d v$ Virol. (2013) 2013:738794. doi: 10.1155/2013/738794

9. Jiang $\mathrm{JH}$, Tong J, Gabriel K. Hijacking mitochondria: bacterial toxins that modulate mitochondrial function. IUBMB Life. (2012) 64:397-401. doi: $10.1002 /$ iub. 1021

10. Seishima M, Mizutani Y, Shibuya Y, Arakawa C. Chronic fatigue syndrome after human parvovirus B19 infection without persistent viremia. Dermatology (2008) 216:341-6. doi: 10.1159/000116723

11. Lloyd-Price J, Mahurkar A, Rahnavard G, Crabtree J, Orvis J, Hall AB, et al. Strains, functions and dynamics in the expanded Human Microbiome Project. Nature (2017) 550:61-6. doi: 10.1038/nature23889

12. Gilbert JA, Blaser MJ, Caporaso JG, Jansson JK, Lynch SV, Knight R, et al. Current understanding of the human microbiome. Nat Med. (2018) 24:392-400. doi: $10.1038 / \mathrm{nm} .4517$

13. Huffnagle GB, Noverr MC. The emerging world of the fungal microbiome. Trends Microbiol. (2013) 21:334-41. doi: 10.1016/j.tim.2013.04.002 are all linked by the activity of the microbiome and its associated proteins/metabolites. A greater focus on these interconnected systems is necessary, which will require increased collaboration between separate research teams.

\section{AUTHOR CONTRIBUTIONS}

AP drafted the manuscript, analyzed and interpreted data, and revised the manuscript for critically important intellectual content. TM drafted parts of the manuscript, analyzed/interpreted data and revised the manuscript for critically important intellectual content.

\section{ACKNOWLEDGMENTS}

The authors would like to acknowledge Michael Eason Kirkpatrick and Janet Raty for their help with graphic design. They also thank Sara Nicole Azevedo for her help with technical editing of the manuscript.

14. Kowarsky M, Camunas-Soler J, Kertesz M, De Vlaminck I, Koh W, Pan W, et al. Numerous uncharacterized and highly divergent microbes which colonize humans are revealed by circulating cell-free DNA. Proc Natl Acad Sci USA. (2017) 114:9623-8. doi: 10.1073/pnas.1707009114

15. Van de Guchte M, Blottière HM, Doré J. Humans as holobionts: implications for prevention and therapy. Microbiome (2018) 6:81. doi: 10.1186/s40168-018-0466-8

16. Postler TS, Ghosh S. Understanding the Holobiont: how microbial metabolites affect human health and shape the immune system. Cell Metab. (2017) 26:110-30. doi: 10.1016/j.cmet.2017.05.008

17. Rogers GB, Keating DJ, Young RL, Wong ML, Licinio J, Wesselingh S. From gut dysbiosis to altered brain function and mental illness: mechanisms and pathways. Mol Psychiatry (2016) 21:738-48. doi: 10.1038/mp. 2016.50

18. Lerner A, Aminov R, Matthias T. Dysbiosis may trigger autoimmune diseases via inappropriate post-translational modification of host proteins. Front Microbiol. (2016) 7:84. doi: 10.3389/fmicb.2016.00084

19. Chen J, Domingue JC, Sears CL. Microbiota dysbiosis in select human cancers: evidence of association and causality. Semin Immunol. (2017) 32:2534. doi: 10.1016/j.smim.2017.08.001

20. Kell DB, Pretorius E. No effects without causes: the iron dysregulation and dormant microbes hypothesis for chronic, inflammatory diseases. Biol Rev Camb Philos Soc. (2018) 93:1518-57. doi: 10.1111/brv. 12407

21. Giloteaux L, Goodrich JK, Walters WA, Levine SM, Ley RE, Hanson MR, et al. Reduced diversity and altered composition of the gut microbiome in individuals with myalgic encephalomyelitis/chronic fatigue syndrome. Microbiome (2016) 4:30. doi: 10.1186/s40168-016-0171-4

22. Proal AD, Lindseth IA, Marshall TG. Microbe-microbe and host-microbe interactions drive microbiome dysbiosis and inflammatory processes. Discov Med. (2017) 23:51-60.

23. Turnbaugh PJ, Ley RE, Hamady M, Fraser-Liggett CM, Knight R, Gordon JI, et al. The human microbiome project. Nature (2007) 449:804-10. doi: 10.1038 /nature 06244

24. Nikkari S, McLaughlin IJ, Bi W, Dodge DE, Relman DA. Does blood of healthy subjects contain bacterial ribosomal DNA? J Clin Microbiol. (2001) 39:1956-9. doi: 10.1128/JCM.39.5.1956-1959. 2001

25. Zou S, Caler L, Colombini-Hatch S, Glynn S, Srinivas P. Research on the human virome: where are we and what is next. Microbiome (2016) 4:32. doi: $10.1186 / s 40168-016-0177-y$ 
26. Koskinen K, Pausan MR, Perras AK, Beck M, Bang C, Mora M. First insights into the diverse human archaeome: specific detection of archaea in the gastrointestinal tract, lung, and nose and on skin. MBio (2017) 8:e00824-17. doi: $10.1128 / \mathrm{mBio} .00824-17$

27. Pfeiffer JK, Virgin HW. Viral immunity. transkingdom control of viral infection and immunity in the mammalian intestine. Science (2016) 351:aad5872. doi: 10.1126/science.aad587

28. Sleator RD. The human superorganism - of microbes and men. Med Hypotheses (2010) 74:214-5. doi: 10.1016/j.mehy.2009.08.047

29. Li J, Jia H, Cai X, Zhong H, Feng Q, Sunagawa S, et al. An integrated catalog of reference genes in the human gut microbiome. Nat Biotechnol. (2014) 32:834-41. doi: 10.1038/nbt.2942

30. O'Dwyer DN, Dickson RP, Moore BB. The lung microbiome, immunity, and the pathogenesis of chronic lung disease. J Immunol. (2016) 196:4839-47. doi: 10.4049/jimmunol.1600279

31. Aagaard K, Ma J, Antony KM, Ganu R, Petrosino J, Versalovic J. The placenta harbors a unique microbiome. Sci Transl Med. (2014) 6:237ra65. doi: 10.1126/scitranslmed.3008599

32. Kenny LC, Kell DB. Immunological tolerance, pregnancy, and preeclampsia: the roles of semen microbes and the father. Front Med. (2018) 4:239. doi: 10.3389/fmed.2017.00239

33. Thomas-White K, Forster SC, Kumar N, Van Kuiken M, Putonti C, Stares $\mathrm{MD}$, et al. Culturing of female bladder bacteria reveals an interconnected urogenital microbiota. Nat Commun. (2018) 9:1557. doi: 10.1038/s41467-018-03968-5

34. Chen C, Song X, Wei W, Zhong H, Dai J, Lan Z, et al. The microbiota continuum along the female reproductive tract and its relation to uterine-related diseases. Nat Commun. (2017) 8:875. doi: 10.1038/s41467-017-00901-0

35. Jakobsen TH, Eickhardt SR, Gheorghe AG, Stenqvist C, Sønderholm M, Stavnsberg $\mathrm{C}$, et al. Implants induce a new niche for microbiomes. APMIS (2018) 2018:2. doi: 10.1111/apm.12862

36. Lluch J, Servant F, Païssé S, Valle C, Valière S, Kuchly C, et al. The characterization of novel tissue microbiota using an optimized 16s metagenomic sequencing pipeline. PLoS ONE (2015) 10:e142334. doi: 10.1371/journal.pone.0142334

37. Gosiewski T, Ludwig-Galezowska AH, Huminska K, Sroka-Oleksiak A, Radkowski P, Salamon D. Comprehensive detection and identification of bacterial DNA in the blood of patients with sepsis and healthy volunteers using next-generation sequencing method - the observation of DNAemia. Eur J Clin Microbiol Infect Dis. (2017) 36:329-36. doi: 10.1007/s10096-016-2805-7

38. Potgieter M, Bester J, Kell DB, Pretorius E. The dormant blood microbiome in chronic, inflammatory diseases. FEMS Microbiol Rev. (2015) 39:567-91. doi: 10.1093/femsre/fuv013

39. Païssé S, Valle C, Servant F, Courtney M, Burcelin R, Amar J, et al. Comprehensive description of blood microbiome from healthy donors assessed by $16 \mathrm{~S}$ targeted metagenomic sequencing. Transfusion (2016) 56:1138-47. doi: 10.1111/trf.13477

40. Moustafa A, Xie C, Kirkness E, Biggs W, Wong E, Turpaz Y, et al. The blood DNA virome in 8,000 humans PLoS Pathog. (2017) 13:e1006292. doi: 10.1371/journal.ppat.1006292

41. Panaiotov S, Filevski G, Equestre M, Nikolova E, Kalfin R. Cultural isolation and characteristics of the blood microbiome of healthy individuals. $A d v$ Microbiol. (2018) 8:406-21. doi: 10.3389/fcimb.2018.00005

42. Whittle E, Leonard MO, Harrison R, Gant TW, Tonge DP. Multi-Method characterisation of the human circulating microbiome. bioRxiv (2018). doi: $10.1101 / 359760$

43. Nuriel-Ohayon M, Neuman H, Koren O. Microbial changes during pregnancy, birth, and infancy. Front Microbiol. (2016) 7:1031. doi: 10.3389/fmicb.2016.01031

44. Gomez-Gallego C, Garcia-Mantrana I, Salminen S, Collado MC. The human milk microbiome and factors influencing its composition and activity. Semin Fetal Neonatal Med. (2016) 21:400-5. doi: 10.1016/j.siny.2016.05.003

45. Brodin P, Jojic V, Gao T, Bhattacharya S, Angel CJ, Furman D, et al. Variation in the human immune system is largely driven by non-heritable influences. Cell (2015) 160:37-47. doi: 10.1016/j.cell.2014
46. Louveau A, Smirnov I, Keyes TJ, Eccles JD, Rouhani SJ, Peske JD, et al. Structural and functional features of central nervous system lymphatic vessels. Nature (2015) 523:337-41. doi: 10.1038/nature14432

47. Benias PC, Wells RG, Sackey-Aboagye B, Klavan H, Reidy J, Buonocore D, et al. Structure and distribution of an unrecognized interstitium in human tissues. Sci Rep. (2018) 8:4947. doi: 10.1038/s41598-018-23062-6

48. Aspelund A, Antila S, Proulx ST, Karlsen TV, Karaman S, Detmar M. A dural lymphatic vascular system that drains brain interstitial fluid and macromolecules. J Exp Med. (2015) 212:991-9. doi: 10.1084/jem.201 42290

49. Da Mesquita S, Louveau A, Vaccari A, Smirnov I, Cornelison RC, Kingsmore $\mathrm{KM}$, et al. Functional aspects of meningeal lymphatics in ageing and Alzheimer's disease. Nature (2018) 25. doi: 10.1038/s41586-018-0368-8

50. Miller-Ensminger T, Garretto A, Brenner J, Thomas-White K, Zambom A, Wolfe AJ, et al. Bacteriophages of the urinary microbiome. J Bacteriol. (2018) 200:e00738-17. doi: 10.1128/JB.00738-17

51. Tatusova T, DiCuccio M, Badretdin A, Chetvernin V, Nawrocki EP, Zaslavsky L. NCBI prokaryotic genome annotation pipeline. Nucleic Acids Res. (2016) 44:6614-24. doi: 10.1093/nar/gkw569

52. Moissl-Eichinger C, Pausan M, Taffner J, Berg G, Bang C, Schmitz RA. Archaea are interactive components of complex microbiomes. Trends Microbiol. (2018) 26:70-85. doi: 10.1016/j.tim.2017.07.004

53. Manuela RP, Cintia C, Georg S, Holger T, Veronika S, Elisabeth S, et al. Measuring the archaeome: detection and quantification of archaea signatures in the human body. bioRxiv (2018) 30. doi: 10.1101/334748

54. Paez-Espino D, Eloe-Fadrosh EA, Pavlopoulos GA, Thomas AD, Huntemann M, Mikhailova N, et al. Uncovering Earth's virome. Nature (2016) 536:42530. doi: 10.1038/nature19094

55. Nguyen S, Baker K, Padman BS, Patwa R, Dunstan RA, Weston TA, et al. Bacteriophage transcytosis provides a mechanism to cross epithelial cell layers. MBio (2017) 8:e1874-17. doi: 10.1128/mBio.01874-17

56. Newberry F, Hsieh SY, Wileman T, Carding SR. Does the microbiome and virome contribute to myalgic encephalomyelitis/chronic fatigue syndrome? Clin Sci. (2018) 132:523-42. doi: 10.1042/CS20171330

57. Paez-Espino D, Chen I, Palaniappan K, Ratner A, Chu K, Szeto E, et al. IMG/VR: a database of cultured and uncultured DNA Viruses and retroviruses. Nucleic Acids Res. (2017) 45:D457-65. doi: $10.1093 / \mathrm{nar} / \mathrm{gkw} 1030$

58. Joint Genome Institute (2018). IMG/VR Database Triples in Size. Available online at: https://jgi.doe.gov/img-vr-vir

59. Chen SH, Garber D, Schaffer P, Knipe DM, Coen DM. Persistent elevated expression of cytokine transcripts in ganglia latently infected with herpes simplex virus in the absence of ganglionic replication or reactivation. Virology (2000) 278:207-16. doi: 10.1006/viro.2000.0643

60. Louca S, Polz M, Mazel F, Albright M, Huber J, O’Connor M, et al. Function and functional redundancy in microbial systems. Nat Ecol Evol. (2018) 2:936-43. doi: 10.1038/s41559-018-0519-1

61. Grzadziel J. Functional redundancy of soil microbiota - does more always mean better? Polish J Soil Sci. (2017) 50:1. doi: 10.17951/pjss/2017.50.1.75

62. Wikoff WR, Anfora A, Liu J, Schultz P, Lesley S, Peters E, et al. Metabolomics analysis reveals large effects of gut microflora on mammalian blood metabolites. Proc Natl Acad Sci USA. (2009) 106:3698-703. doi: 10.1073/pnas.0812874106

63. Brenu EW, Hardcastle S, Atkinson G, van Driel M, KreijkampKaspers S, Ashton K, et al. Natural killer cells in patients with severe chronic fatigue syndrome. Auto Immun Highlights (2013) 4:69-80. doi: 10.1007/s13317-013-0051-x

64. Ma C, Han M, Heinrich B, Fu Q, Zhang Q, Sandhu M, et al. Gut microbiomemediated bile acid metabolism regulates liver cancer via NKT cells. Science (2018) 360:eaan5931. doi: 10.1126/science.aan5931

65. Yamane T, Sakamoto T, Nakagaki T, Nakano Y. Lactic acid bacteria from kefir increase cytotoxicity of natural killer cells to tumor cells. Foods (2018) 7:E48 doi: 10.3390/foods7040048

66. Rothhammer V, Mascanfroni I, Bunse L, Takenaka M, Kenison J, Mayo L, et al. Type I interferons and microbial metabolites of tryptophan modulate astrocyte activity and central nervous system inflammation via the aryl hydrocarbon receptor. Nat Med. (2016) 22:586-97. doi: 10.1038/nm.4106 
67. Newton J, Okonkwo O, Sutcliffe K, Seth A, Shin J, Jones D. Symptoms of autonomic dysfunction in chronic fatigue syndrome. QJM (2007) 100:51926. doi: 10.1093/qjmed/hcm057

68. Cambras T, Castro-Marrero J, Zaragoza M, Díez-Noguera A, Alegre J. Circadian rhythm abnormalities and autonomic dysfunction in patients with Chronic Fatigue Syndrome/Myalgic Encephalomyelitis. PLoS ONE (2018) 13:e0198106. doi: 10.1371/journal.pone.0198106

69. Pluznick J, Protzko R, Gevorgyan H, Peterlin Z, Sipos A, Han J, et al. Olfactory receptor responding to gut microbiota-derived signals plays a role in renin secretion and blood pressure regulation. Proc Natl Acad Sci USA. (2013) 110:4410-5. doi: 10.1073/pnas.1215927110

70. Rizzo R, Soffritti I, D’Accolti M, Bortolotti D, Di Luca D, Caselli E. Infection of NK cells modulates the expression of miRNAs and transcription factors potentially associated to impaired NK activity. Front Microbiol. (2017) 8:2143. doi: $10.3389 /$ fmicb.2017.02143

71. Masaki T, Qu J, Cholewa-Waclaw J, Burr K, Raaum R, Rambukkana A. Reprogramming adult Schwann cells to stem cell-like cells by leprosy bacilli promotes dissemination of infection. Cell (2013) 152:51-67. doi: 10.1016/j.cell.2012.12.014

72. Liu Y, Liu F, Guan Z, Dong F, Cheng J, Gao Y. The extracellular domain of Staphylococcus aureus LtaS binds insulin and induces insulin resistance during infection. Nat Microbiol. (2018) 3:622-31. doi: 10.1038/s41564-018-0146-2

73. Irie Y, Parsek M. Quorum sensing and microbial biofilms. Curr Top Microbiol Immunol. (2008) 322:67-84.

74. Humphries J, Xiong L, Liu J, Prindle A, Yuan F, Arjes HA, et al. Speciesindependent attraction to biofilms through electrical signaling. Cell (2017) 168:200-209.e12. doi: 10.1016/j.cell.2016.12.014

75. De Sordi L, Lourenço M, Debarbieux L. "I will survive": a tale of bacteriophage-bacteria coevolution in the gut. Gut Microbes (2018) 18:1-18. doi: 10.1080/19490976.2018.1474322

76. Jones M, Watanabe M, Zhu S, Graves C, Keyes L, Grau K, et al. Enteric bacteria promote human and mouse norovirus infection of B cells. Science (2014) 346:755-9. doi: 10.1126/science.1257147

77. Petersen C, Round J. Defining dysbiosis and its influence on host immunity and disease. Cell Microbiol. (2014) 16:1024-33. doi: 10.1111/cmi.12308

78. Li B, Selmi C, Tang R, Gershwin M, Ma X. The microbiome and autoimmunity: a paradigm from the gut-liver axis. Cell Mol Immunol. (2018) 15:595-609. doi: 10.1038/cmi.2018.7

79. Sampson T, Debelius J, Thron T, Janssen S, Shastri G, Ilhan Z, et al. Gut microbiota regulate motor deficits and neuroinflammation in a model of Parkinson's Disease. Cell (2016) 167:1469-80.e12. doi: 10.1016/j.cell.2016

80. Wang X, Yang Y, Huycke M. Microbiome-driven carcinogenesis in colorectal cancer: models and mechanisms. Free Radic Biol Med. (2016) 105:3-15. doi: 10.1016/j.freeradbiomed.10.504

81. Urbaniak C, Gloor G, Brackstone M, Scott L, Tangney M, Reid G. The microbiota of breast tissue and its association with breast cancer. Appl Environ Microbiol. (2016) 82:5039-48. doi: 10.1128/AEM.01235-16

82. Zimmermann A, Knecht H, Häsler R, Zissel G, Gaede KI, Hofmann et al. Atopobium and Fusobacterium as novel candidates for sarcoidosis-associated microbiota. Eur Respir J. (2017) 50:1600746. doi: 10.1183/13993003.00746-2016

83. Zhao G, Vatanen T, Droit L, Park A, Kostic A, Poon T, et al. Intestinal virome changes precede autoimmunity in type I diabetes-susceptible children. Proc Natl Acad Sci USA. (2017) 114:E6166-75. doi: 10.1073/pnas.17063 59114

84. Nagy-Szakal D, Williams BL, Mishra N, Che X, Lee B, Bateman L, et al. Fecal metagenomic profiles in subgroups of patients with myalgic encephalomyelitis/chronic fatigue syndrome. Microbiome (2017) 5:44. doi: 10.1186/s40168-017-0261-y

85. Caporaso J, Lauber C, Costello E, Berg-Lyons D, Gonzalez A, Stombaugh J, et al. Moving pictures of the human microbiome. Genome Biol. (2011) 12:R50. doi: 10.1186/gb-2011-12-5-r50

86. Frémont M, Coomans D, Massart S, De Meirleir K. High-throughput $16 \mathrm{~S}$ rRNA gene sequencing reveals alterations of intestinal microbiota in myalgic encephalomyelitis/chronic fatigue syndrome patients. Anaerobe (2013) 22:50-6. doi: 10.1016/j.anaerobe.2013.06.002
87. Olde Loohuis L, Mangul S, Ori AP, Jospin G, Koslicki D, Yang HT, et al. Transcriptome analysis in whole blood reveals increased microbial diversity in schizophrenia. Transl Psychiatry. (2018) 8:96. doi: 10.1038/s41398-018-0107-9

88. Readhead B, Haure-Mirande J, Funk C, Richards M, Shannon P, Haroutunian V. Multiscale Analysis of independent Alzheimer's cohorts finds disruption of molecular, genetic, and clinical networks by human herpesvirus. Neuron (2018) 99:64-82.e7. doi: 10.1016/j.neuron.05.023

89. Pisa D, Alonso R, Rábano A, Rodal I, Carrasco L. Different brain regions are infected with fungi in Alzheimer's disease. Sci Rep. (2015) 5:15015 doi: $10.1038 /$ srep 15015

90. Alonso R, Pisa D, Fernández-Fernández A, Carrasco L. Infection of fungi and bacteria in brain tissue from elderly persons and patients with Alzheimer's disease. Front Aging Neurosci. (2018) 10:159. doi: 10.3389/fnagi.2018. 00159

91. Branton WG, Ellestad KK, Maingat F, Wheatley BM, Rud E, Warren $\mathrm{RL}$, et al. Brain microbial populations in HIV/AIDS: $\alpha$-proteobacteria predominate independent of host immune status. PLoS ONE (2013) 8:e54673. doi: 10.1371/journal.pone.0054673

92. Duerkop BA, Kleiner M, Paez-Espino D, Zhu W, Bushnell B, Hassell B, et al. Murine colitis reveals a disease-associated bacteriophage community. Nat Microbiol. (2018) 23. doi: 10.1038/s41564-018-0210-y

93. Tetz G, Brown S, Hao Y, Tetz V. Parkinson's disease and bacteriophages as its overlooked contributors. Sci Rep. (2018) 8:10812. doi: 10.1038/s41598-018-29173-4

94. Schutzer SE, Angel T, Liu T, Schepmoes A, Clauss T, Adkins J, et al. Distinct cerebrospinal fluid proteomes differentiate post-treatment lyme disease from chronic fatigue syndrome. PLoS ONE (2011) 6:e17287. doi: 10.1371/journal.pone.001728

95. Naviaux RK, Naviaux JC, Li K, Bright AT, Alaynick WA, Wang L, et al. Metabolic features of chronic fatigue syndrome. Proc Natl Acad Sci USA. (2016) 113:E5472-80. doi: 10.1073/pnas.1607571113

96. Johnson CH, Dejea CM, Edler D, Hoang LT, Santidrian AF, Felding BH, et al. Metabolism links bacterial biofilms and colon carcinogenesis. Cell Metab. (2015) 21:891-7. doi: 10.1016/j.cmet.2015.04.011

97. Eastment MC, McClelland R. Vaginal microbiota and susceptibility to HIV. AIDS. (2018) 32:687-98. doi: 10.1097/QAD.00000000000 01768

98. Chow J, Tang H, Mazmanian S. Pathobionts of the gastrointestinal microbiota and inflammatory disease. Curr Opin Immunol. (2011) 23:47380. doi: 10.1016/j.coi.2011.07.010

99. Zechner E. Inflammatory disease caused by intestinal pathobionts. Curr Opin Microbiol. (2017) 35:64-9. doi: 10.1016/j.mib.2017.01.011

100. Yost S, Duran-Pinedo AE, Teles R, Krishnan K, Frias-Lopez J. Functional signatures of oral dysbiosis during periodontitis progression revealed by microbial metatranscriptome analysis. Genome Med. (2015) 7:27. doi: 10.1186/s13073-015-0153-3

101. Weiser J, Ferreira D, Paton J. Streptococcus pneumoniae: transmission, colonization and invasion. Nat Rev Microbiol. (2018) 16:355-67. doi: 10.1038/s41579-018-0001-8

102. Krismer B, Weidenmaier C, Zipperer A, Peschel A. The commensal lifestyle of Staphylococcus aureus and its interactions with the nasal microbiota. Nat Rev Microbiol. (2017) 15:675-87. doi: 10.1038/nrmicro.2017.104

103. Miskinyte M, Sousa A, Ramiro R, de Sousa J, Kotlinowski J, Caramalho I. The genetic basis of Escherichia coli pathoadaptation to macrophages. PLoS Pathog. (2013) 9:e1003802. doi: 10.1371/journal.ppat.1003802

104. Hottes A, Freddolino P, Khare A, Donnell Z, Liu J, Tavazoie S. Bacterial adaptation through loss of function. PLoS Genet. (2013) 9:e1003617. doi: 10.1371/journal.pgen.1003617

105. Cullen L, McClean S. Bacterial adaptation during chronic respiratory infections. Pathogens (2015) 4:66-89. doi: 10.3390/pathogens4010066

106. Greenblum S, Carr R, Borenstein E. Extensive strain-level copy-number variation across human gut microbiome species. Cell (2015) 160:583-94. doi: 10.1016/j.cell.2014.12.038

107. Yao L, Seaton S, Ndousse-Fetter S, Adhikari A, DiBenedetto N, Mina AI, et al. A selective gut bacterial bile salt hydrolase alters host metabolism. Elife (2018) 7:e37182. doi: 10.7554/eLife.37182 
108. VanElzakker M. Chronic fatigue syndrome from vagus nerve infection: a psychoneuroimmunological hypothesis. Med Hypotheses (2013) 81:414-23. doi: 10.1016/j.mehy.2013.05.034

109. Hajishengallis G, Darveau R, Curtis M. The keystone-pathogen hypothesis. Nat Rev Microbiol. (2012) 10:717-25. doi: 10.1038/nrmicro2873

110. Hajishengallis G, Liang S, Payne M, Hashim A, Jotwani R, Eskan M. Lowabundance biofilm species orchestrates inflammatory periodontal disease through the commensal microbiota and complement. Cell Host Microbe (2011) 10:497-506. doi: 10.1016/j.chom.2011.10.006

111. Kell D, Potgieter M, Pretorius E. Individuality, phenotypic differentiation, dormancy and 'persistence' in culturable bacterial systems: commonalities shared by environmental, laboratory, and clinical microbiology. Version 2. F1000Res. (2015) 4:179. doi: 10.12688/f1000research.6709

112. Ercoli G, Fernandes V, Chung W, Wanford J, Thomson S, Bayliss C, et al. Intracellular replication of Streptococcus pneumoniae inside splenic macrophages serves as a reservoir for septicaemia. Nat Microbiol. (2018) 3:600-10. doi: 10.1038/s41564-018-0147-1

113. Indrio F, Martini S, Francavilla R, Corvaglia L, Cristofori F, Mastrolia S, et al. Epigenetic matters: the link between early nutrition, microbiome, and long-term health development. Front Pediatr. (2017) 5:178. doi: $10.3389 /$ fped.2017.00178

114. Xu Y, Xie J, Li Y, Yue J, Chen J, Chunyu L, et al. Using a cDNA microarray to study cellular gene expression altered by Mycobacterium tuberculosis. Chin Med J. (2003) 116:1070-3.

115. Hanada K, Uchida T, Tsukamoto Y, Watada M, Yamaguchi N, Yamamoto K, et al. Helicobacter pylori infection introduces DNA double-strand breaks in host cells. Infect Immun. (2014) 82:4182-9. doi: 10.1128/IAI.02368-14

116. Hafez A, Luftig M. Characterization of the EBV-induced persistent DNA damage response. Viruses. (2017) 9:E366. doi: 10.3390/v9120366

117. Wynendaele E, Verbeke F, D'Hondt M, Hendrix A, Van De Wiele C, Burvenich C, et al. Crosstalk between the microbiome and cancer cells by quorum sensing peptides. Peptides (2015) 64:40-8. doi: 10.1016/j.peptides.2014.12.009

118. Rustom A, Saffrich R, Markovic I, Walther P, Gerdes H. Nanotubular highways for intercellular organelle transport. Science. (2004) 303:1007-10. doi: $10.1126 /$ science.1093133

119. Hashimoto M, Bhuyan F, Hiyoshi M, Noyori O, Nasser H, Miyazaki $\mathrm{M}$, et al. Potential role of the formation of tunneling nanotubes in HIV-1 spread in macrophages. J Immunol. (2016) 196:1832-41. doi: 10.4049/jimmunol.1500845

120. Zhu S, Victoria G, Marzo L, Ghosh R, Zurzolo C. Prion aggregates transfer through tunneling nanotubes in endocytic vesicles. Prion (2015) 9:125-35. doi: 10.1080/19336896.2015.1025189

121. Haimovich G, Ecker C, Dunagin M, Eggan E, Raj A, Gerst J, et al. Intercellular mRNA trafficking via membrane nanotube-like extensions in mammalian cells. Proc Natl Acad Sci USA. (2017) 114:E9873-82. doi: 10.1073/pnas.1706365114

122. Altindis E, Cai W, Sakaguchi M, Zhang F, GuoXiao W, Liu F, et al. Viral insulin-like peptides activate human insulin and IGF-1 receptor signaling: A paradigm shift for host-microbe interactions. Proc Natl Acad Sci USA. (2018) 115:2461-6. doi: 10.1073/pnas.1721117115

123. Xia J, Chiu L, Nehring RB, Bravo Nunez MA, Mei Q, Perez M. Bacteria-tohuman protein networks reveal origins of endogenous DNA damage. bioRxiv (2018) 26. doi: 10.1101/354589

124. Nolte-'t Hoen E, Cremer T, Gallo R, Margolis L. Extracellular vesicles and viruses: Are they close relatives? Proc Natl Acad Sci USA. (2016) 113:9155-61. doi: $10.1073 /$ pnas.1605146113

125. Wang T, Tavera-Mendoza L, Laperriere D, Libby E, MacLeod N, Nagai $\mathrm{Y}$, et al. Large-scale in silico and microarray-based identification of direct 1,25-dihydroxyvitamin D3 target genes. Mol Endocrinol. (2005) 19:2685-95. doi: 10.1210/me.2005-0106

126. Wu S, Sun J. Vitamin D, vitamin D receptor, and macroautophagy in inflammation and infection. Discov Med. (2011) 11:325-35.

127. Meyer V, Saccone D, Tugizimana F, Asani F, Jeffery T, Bornman L. Methylation of the Vitamin D Receptor (VDR) gene, together with genetic variation, race, and environment influence the signaling efficacy of the toll-like receptor 2/1-VDR pathway. Front Immunol. (2017) 8:1048. doi: $10.3389 /$ fimmu.2017.01048
128. Yenamandra S, Lundin A, Arulampalam V, Yurchenko M, Pettersson S, Klein G, et al. Expression profile of nuclear receptors upon Epstein - Barr virus induced B cell transformation. Exp Oncol. (2009) 31:92-6.

129. Nevado J, Tenbaum S, Castillo A, Sánchez-Pacheco A, Aranda A. Activation of the human immunodeficiency virus type I long terminal repeat by 1 alpha,25-dihydroxyvitamin D3. J Mol Endocrinol. (2007) 38:587-601. doi: 10.1677/JME-06-0065

130. Chan G, Bivins-Smith E, Smith M, Smith P, Yurochko A. Transcriptome analysis reveals human cytomegalovirus reprograms monocyte differentiation toward an M1 macrophage. J Immunol. (2008) 181:698-711.

131. Salazar J, Duhnam-Ems S, La Vake C, Cruz A, Moore M, Caimano M, et al. Activation of human monocytes by live Borrelia burgdorferi generates TLR2-dependent and -independent responses which include induction of IFN-beta. PLoS Pathog (2009) 5:e1000444. doi: 10.1371/journal.ppat.10 00444

132. Liu PT, Wheelwright M, Teles R, Komisopoulou E, Edfeldt K, Ferguson B, et al. MicroRNA-21 targets the vitamin D-dependent antimicrobial pathway in leprosy. Nat Med. (2012) 18:267-73. doi: 10.1038/nm.2584

133. Coughlan C, Chotirmall S, Renwick J, Hassan T, Low T, Bergsson G, et al. The effect of Aspergillus fumigatus infection on vitamin $\mathrm{D}$ receptor expression in cystic fibrosis. Am J Respir Crit Care Med. (2012) 186:999-1007. doi: 10.1164/rccm.201203-0478OC

134. Pushalkar S, Hundeyin M, Daley D, Zambirinis C, Kurz E, Mishra A, et al. The pancreatic cancer microbiome promotes oncogenesis by induction of innate and adaptive immune suppression. Cancer Discov. (2018) 8:403-16. doi: 10.1158/2159-8290.CD-17-1134

135. Munoz JF, Delorey T., Ford CB, Li BY, Thompson DA, Rao RP, et al. Coordinated host-pathogen transcriptional dynamics revealed using sorted subpopulations and single, Candida albicans infected macrophages. bioRxiv (2018) 350322. doi: 10.1101/350322

136. McKinney EF, Lee JC, Jayne DR, Lyons PA, Smith KG. T-cell exhaustion, co-stimulation and clinical outcome in autoimmunity and infection. Nature (2015) 523:612-6. doi: 10.1038/nature14468

137. Sen DR, Kaminski J, Barnitz RA, Kurachi M, Gerdemann U, Yates KB, et al. The epigenetic landscape of T cell exhaustion. Science (2016) 354:1165-9. doi: 10.1126/science.aae0491

138. Cameron D. Proof that chronic lyme disease exists. Interdiscip Perspect Infect Dis. (2010) 2010:876450. doi: 10.1155/2010/876450

139. Aid M, Abbink P, Larocca R, Boyd M, Nityanandam R, Nanayakkara O, et al. Zika virus persistence in the central nervous system and lymph nodes of rhesus monkeys. Cell (2017) 169:610-20.e14. doi: 10.1016/j.cell.2017. 04.008

140. Wilson H, Amo-Addae M, Kenu E, Ilesanmi O, Ameme D, Sackey $\mathrm{S}$. post-ebola syndrome among ebola virus disease survivors in Montserrado County, Liberia. Biomed Res Int. (2016) 2018:1909410. doi: $10.1155 / 2018 / 1909410$

141. Fischer W, Brown J, Wohl D, Loftis A, Tozay S, Reeves E, et al. Ebola virus ribonucleic acid detection in semen more than two years after resolution of acute ebola virus infection. Open Forum Infect Dis. (2017) 4:ofx155. doi: 10.1093/ofid/ofx155

142. Hosseini S, Wilk E, Michaelsen-Preusse K, Gerhauser I, Baumgärtner W, Geffers R, et al. Long-term neuroinflammation induced by influenza a virus infection and the impact on hippocampal neuron morphology and function. J Neurosci. (2018) 38:3060-80. doi: 10.1523/JNEUROSCI.1740-17.2018

143. Viola M, Scott C, Duffy P. Persistent measles virus infection in vitro and in man. Arthritis Rheum. (1978) 21(Suppl. 5):S47-51.

144. Wakefield A, Ekbom A, Dhillon A, Pittilo R, Pounder R. Crohn's disease: pathogenesis and persistent measles virus infection. Gastroenterology (1995) 108:911-6.

145. Griffin D, Lin W, Pan C. Measles virus, immune control, and persistence. FEMS Microbiol Rev. (2012) 36:649-62. doi: 10.1111/j.1574-6976.2012.00330.x

146. Doi T, Kwon H, Honda T, Sato H, Yoneda M, Kai C. Measles virus induces persistent infection by autoregulation of viral replication. Sci Rep. (2016) 6:37163. doi: $10.1038 /$ srep37163

147. Casadesús J. Bacterial L-forms require peptidoglycan synthesis for cell division. Bioessays (2007) 29:1189-91. doi: 10.1002/bies.20680 
148. Glover W, Yang Y, Zhang Y. Insights into the molecular basis of L-form formation and survival in Escherichia coli. PLoS ONE (2009) 4:e7316. doi: 10.1371/journal.pone.0007316

149. Markova N. L-form bacteria cohabitants in human blood: significance for health and diseases. Discov Med. (2017) 23:305-13.

150. Mattman LH.(2000). Cell Wall Deficient Forms: Stealth Pathogens. Boca Raton, FL: CRC Press.

151. Bruno R, Creange S, Frick N. Parallels between post-polio fatigue and chronic fatigue syndrome: a common pathophysiology? Am J Med. (1998) 105:66S-73S.

152. Straus SE. The chronic mononucleosis syndrome. J Infect Dis. (1988) 157:405-12.

153. Archer M. The post-viral syndrome: a review. J R Coll Gen Pract. (1987) 37:212-4.

154. Chia J, Chia A, Voeller M, Lee T, Chang R. Acute enterovirus infection followed by myalgic encephalomyelitis/chronic fatigue syndrome (ME/CFS) and viral persistence. J Clin Pathol. (2010) 63:165-8. doi: $10.1136 /$ jcp.2009.070466

155. Chang C, Crane M, Zhou J, Mina M, Post J, Cameron B, et al. HIV and co-infections. Immunol Rev. (2013) 254:114-42. doi: 10.1111/imr.12063

156. Bedard P, Hansen A, Ratain M, Siu L. Tumour heterogeneity in the clinic. Nature (2013) 501:355-64. doi: 10.1038/nature12627

157. Proal A, Albert P, Marshall T. Autoimmune disease and the human metagenome. ed. Nelson KE. Metagen Hum Body (2010) 231-75. doi: 10.1007/978-1-4419-7089-3_12

158. Mina M, Metcalf C, de Swart R, Osterhaus A, Grenfell B. Long-term measlesinduced immunomodulation increases overall childhood infectious disease mortality. Science (2015) 348:694-9. doi: 10.1126/science.aaa3662

159. Cabrera-Rubio R, Collado M, Laitinen K, Salminen S, Isolauri E, Mira A. The human milk microbiome changes over lactation and is shaped by maternal weight and mode of delivery. Am J Clin Nutr. (2012) 96:544-51. doi: 10.3945/ajcn.112.037382

160. Tomlinson MS, Bommarito PA, Martin EM, Smeester L, Fichorova RN, Onderdonk AB, et al. Microorganisms in the human placenta are associated with altered $\mathrm{CpG}$ methylation of immune and inflammation-related genes. PLoS ONE (2017) 12:e0188664. doi: 10.1371/journal.pone.0188664

161. Langdon A, Crook N, Dantas G. The effects of antibiotics on the microbiome throughout development and alternative approaches for therapeutic modulation.Genome Med. (2016) 8:39. doi: 10.1186/s13073-0160294-z

162. Vignaroli C, Zandri G, Aquilanti L, Pasquaroli S, Biavasco F. Multidrugresistant enterococci in animal meat and faeces and co-transfer of resistance from an Enterococcus durans to a human Enterococcus faecium. Curr Microbiol. (2011) 62:1438-47. doi: 10.1007/s00284-011-9880-x

163. Kolomytseva M, Gapeev A, Sadovnikov V, Chemeris N. Suppression of nonspecific resistance of the body under the effect of extremely high frequency electromagnetic radiation of low intensity. Biofizika (2002) 47:71-7.

164. Diaz P, Hong BY, Frias-Lopez J, Dupuy AK, Angeloni M, Abusleme L, et al. Transplantation-associated long-term immunosuppression promotes oral colonization by potentially opportunistic pathogens without impacting other members of the salivary bacteriome. Clin Vaccine Immunol. (2013) 20:920-30. doi: 10.1128/CVI.00734-12

165. Tatem AJ, Rogers DJ, Hay SI. Global transport networks and infectious disease spread. Adv Parasitol. (2006) 62:293-343. doi: 10.1016/S0065-308X(05)62009-X

166. Jansen W, Woudstra S, Müller A, Grabowski N, Schoo G, Gerulat B. The safety and quality of pork and poultry meat imports for the common European market received at border inspection post Hamburg Harbour between 2014 and 2015. PLOS ONE (2018) 13:e0192550. doi: 10.1371/journal.pone.0192550

167. Feazel LM, Baumgartner LK, Peterson KL, Frank DN, Harris JK, Pace NR. Opportunistic pathogens enriched in showerhead biofilms. Proc Natl Acad Sci USA. (2009) 106:16393-9. doi: 10.1073/pnas.0908446106

168. Sapkota AR, Berger S, Vogel TM. Human pathogens abundant in the bacterial metagenome of cigarettes. Environ Health Perspect. (2010) 118:3516. doi: 10.1289/ehp.0901201
169. Twisk FN. The status of and future research into Myalgic Encephalomyelitis and Chronic Fatigue Syndrome: the need of accurate diagnosis, objective assessment, and acknowledging biological and clinical subgroups. Front Physiol. (2014) 5:109. doi: 10.3389/fphys.2014.00109

170. Lantos PM. Chronic Lyme disease. Infect Dis Clin North Am. (2015) 29:32540. doi: 10.1016/j.idc.02.006

171. Halpin P, Williams MV, Klimas NG, Fletcher MA, Barnes Z, Ariza ME. Myalgic encephalomyelitis/chronic fatigue syndrome and gulf war illness patients exhibit increased humoral responses to the herpesviruses-encoded dUTPase: Implications in disease pathophysiology. J Med Virol. (2017) 89:1636-45. doi: 10.1002/jmv.24810

172. Hakim A, De Wandele I, O'Callaghan C, Pocinki A, Rowe P. Chronic fatigue in Ehlers-Danlos syndrome-Hypermobile type. Am J Med Genet C Semin Med Genet. (2017) 175:175-80. doi: 10.1002/ajmg.c.31542

173. Castro-Marrero J, Faro M, Aliste L, Sáez-Francàs N, Calvo N, MartínezMartínez A. Comorbidity in chronic fatigue syndrome/myalgic encephalomyelitis: a nationwide population-based cohort study. Psychosomatics (2017) 58:533-43. doi: 10.1016/j.psym.2017. 04.010

174. Treib J, Grauer MT, Haass A, Langenbach J, Holzer G, Woessner R. Chronic fatigue syndrome in patients with Lyme borreliosis. Eur Neurol. (2000) 43:107-9. doi: 10.1159/000008144

175. Blomberg J, Gottfries CG, Elfaitouri A, Rizwan M, Rosén A. Infection elicited autoimmunity and myalgic encephalomyelitis/chronic fatigue syndrome: an explanatory model. Front Immunol. (2018) 9:229. doi: 10.3389/fimmu.2018.00229

176. Proal AD, Marshall TG. Re-framing the theory of autoimmunity in the era of the microbiome: persistent pathogens, autoantibodies, and molecular mimicry. Discov Med. (2018) 25:299-308.

177. Vojdani A, Vojdani E, Saidara E, Kharrazian D. Reaction of amyloid- $\beta$ peptide antibody with different infectious agents involved in alzheimer's disease. J Alzheimers Dis. (2018) 63:847-60. doi: 10.3233/JAD-170961

178. Manfredo V, Hiltensperger M, Kumar V, Zegarra-Ruiz D, Dehner C, Khan N. Translocation of a gut pathobiont drives autoimmunity in mice and humans. Science (2018) 359:1156-61. doi: 10.1126/science.aar7201

179. Tuffs SW, Haeryfar SM, McCormick JK. Manipulation of innate and adaptive immunity by staphylococcal superantigens. Pathogens (2018) 7:E53. doi: 10.3390/pathogens7020053

180. Carabotti M, Scirocco A, Maselli M, Severi C. The gut-brain axis: interactions between enteric microbiota, central and enteric nervous systems. Ann Gastroenterol. (2015) 28:203-9.

181. Mayer EA. Gut feelings: the emerging biology of gut-brain communication. Nat Rev Neurosci. (2011) 12:453-66. doi: 10.1038/nrn307

182. Soscia SJ, Kirby JE, Washicosky KJ, Tucker SM, Ingelsson M, Hyman B, et al. The Alzheimer's disease-associated amyloid beta-protein is an antimicrobial peptide. PLoS ONE (2010) 5:e9505. doi: 10.1371/journal.pone.0009505

183. Pasupuleti $M$, Roupe $M$, Rydengård V, Surewicz K, Surewicz WK, Chalupka A, et al. Antimicrobial activity of human prion protein is mediated by its N-terminal region. PLoS ONE (2009) 4:e7358. doi: 10.1371/journal.pone.0007358

184. Kumar DK, Choi SH, Washicosky KJ, Eimer WA, Tucker S, Ghofrani J, et al. Amyloid- $\beta$ peptide protects against microbial infection in mouse and worm models of Alzheimer's disease. Sci Transl Med. (2016) 8:340ra72. doi: 10.1126/scitranslmed.aaf1059

185. Eimer WA, Vijaya Kumar DK, Navalpur Shanmugam NK, Rodriguez AS, Mitchell T, Washicosky KJ, et al. Alzheimer's disease-associated $\beta$-amyloid is rapidly seeded by herpesviridae to protect against brain infection. Neuron (2018) 99:56-63.e3. doi: 10.1016/j.neuron.2018.06.030

186. Itzhaki RF, Lathe R, Balin BJ, Ball MJ, Bearer EL, Braak H. Microbes and Alzheimer's disease. J Alzheimers Dis. (2016) 51:979-84. doi: 10.3233/JAD-160152

187. Zeineh MM, Kang J, Atlas SW, Raman MM, Reiss AL, Norris JL, et al. Right arcuate fasciculus abnormality in chronic fatigue syndrome. Radiology (2015) 274:517-26. doi: 10.1148/radiol.14141079

188. Gottlieb B, Chalifour LE, Mitmaker B, Sheiner N, Obrand D, Abraham C. BAK1 gene variation and abdominal aortic aneurysms. Hum Mutat. (2009) 30:1043-7. doi: 10.1002/humu.21046 
189. Ursini G, Punzi G, Chen Q, Marenco S, Robinson J, Porcelli A, et al. Convergence of placenta biology and genetic risk for schizophrenia. Nat Med. (2018) 24:792-801. doi: 10.1038/s41591-018-0021-y

190. Harley JB, Chen X, Pujato M, Miller D, Maddox A, Forney $\mathrm{C}$, et al. Transcription factors operate across disease loci, with EBNA2 implicated in autoimmunity. Nat Genet. (2018) 50:699-707. doi: 10.1038/s41588-018-0102-3

191. Proal AD, Albert PJ, Marshall TG. The human microbiome and autoimmunity. Curr Opin Rheumatol. (2013) 25:234-40. doi: 10.1097/BOR.0b013e32835cedbf

192. Kell DB, Pretorius E. On the translocation of bacteria and their lipopolysaccharides between blood and peripheral locations in chronic, inflammatory diseases: the central roles of LPS and LPS-induced cell death. Integr Biol. (2015) 7:1339-77. doi: 10.1039/c5ib00158g

193. Sharma SK, Soneja M. HIV \& immune reconstitution inflammatory syndrome (IRIS). Indian J Med Res. (2011) 134:866-77. doi: 10.4103/0971-5916.92632

194. Maude S, Barrett D, Teachey DT, Grupp SA. Managing cytokine release syndrome associated with novel T cell-engaging therapies. Cancer J. (2014) 20:119-22. doi: 10.1097/PPO.0000000000000035

195. Arando M, Fernandez-Naval C, Mota-Foix M, Alvarez A, Armegol P, Barberá MJ, et al. The Jarisch-Herxheimer reaction in syphilis: could molecular typing help to understand it better? J Eur Acad Dermatol Venereol. (2018). 32:1791-5. doi: 10.1111/jdv.15078.

196. Farmer TW. Jarisch-herxheimer reaction in early syphilis. JAMA (1948) 138:480-5. doi: 10.1001/jama.1948.02900070012003

197. Meintjes G, Rabie H,., Wilkinson RJ, Cotton MF. Tuberculosis-associated immune reconstitution inflammatory syndrome and unmasking of tuberculosis by antiretroviral therapy. Clin Chest Med. (2009) 30:797-810. doi: 10.1016/j.ccm.2009.08.013

198. Müller M, Wandel S, Colebunders R, Attia S, Furrer H, Egger M. IeDEA Southern and Central Africa Immune reconstitution inflammatory syndrome in patients starting antiretroviral therapy for HIV infection: a systematic review and meta-analysis. Lancet Infect Dis. (2010) 10:251-61. doi: 10.1016/S1473-3099(10) 70026-8

199. Proal AD, Albert PJ, Marshall TG, Blaney GP, Lindseth IA Immunostimulation in the treatment for chronic fatigue syndrome/myalgic encephalomyelitis. Immunol Res. (2013) 56:398-412. doi: 10.1007/s12026-013-8413-z

200. Proal AD, Albert PJ, Blaney GP, Lindseth IA, Benediktsson C, Marshall TG. Immunostimulation in the era of the metagenome. Cell Mol Immunol. (2011) 8:213-25. doi: $10.1038 / \mathrm{cmi} .2010 .77$

201. Shimabukuro-Vornhagen A, Gödel P, Subklewe M, Stemmler H, Schlößer H, Schlaak M. Cytokine release syndrome. J Immunother Cancer (2018) 6:56. doi: 10.1186/s40425-018-0343-9

202. Roberts E, Wessely S, Chalder T, Chang CK, Hotopf M. Mortality of people with chronic fatigue syndrome: a retrospective cohort study in England and Wales from the South London and Maudsley NHS Foundation Trust Biomedical Research Centre (SLaM BRC) Clinical Record Interactive Search (CRIS) Register. Lancet (2016) 387:1638-43. doi: 10.1016/S0140-6736(15) 01223-4

Conflict of Interest Statement: The authors declare that the research was conducted in the absence of any commercial or financial relationships that could be construed as a potential conflict of interest.

Copyright (c) 2018 Proal and Marshall. This is an open-access article distributed under the terms of the Creative Commons Attribution License (CC BY). The use, distribution or reproduction in other forums is permitted, provided the original author(s) and the copyright owner(s) are credited and that the original publication in this journal is cited, in accordance with accepted academic practice. No use, distribution or reproduction is permitted which does not comply with these terms. 